\title{
MAPAC: Um Método de Análise de Processos para Aproximação Cidadã
}

\section{Title: MAPAC: Process Analysis for Citizen Approach Method}

\author{
Emmanuel Pires ${ }^{1,2}$, Renata Araujo ${ }^{2}$ \\ ${ }^{1}$ Programa de Pós-Graduação em Informática (UNIRIO) \\ Av. Pasteur 458, Urca, 22290-240, Rio de Janeiro - RJ - Brazil \\ ${ }^{2}$ Grupo de Pesquisa e Inovação em Ciberdemocracia (CIBERDEM)
}

Faculdade de Computação e Informática - Universidade Presbiteriana Mackenzie - Rua da Consolação, 930, Consolação, 02402-907, São Paulo, SP.

\{emmanuel.pires@uniriotec.br, renata.araujo@mackenzie.br\}

\begin{abstract}
The use of Information and Communication Technologies has been understood as an important mean for public organizations to provide quality services to citizens, reducing the gap among public administration and its clients. This paper describes the Process Analysis for Citizen Approach Method (MAPAC), which aims to guide a process analyst to identify and propose solutions in order to reduce the gap between citizens and the public process. Two studies were carried out to evaluate MAPAC, one at the National Cancer Institute (INCA) in Brazil and another at a specialized unit in conflict mediation at the Rio de Janeiro Court of Justice (TJRJ). The results have describe the method potential to support the identification of alternatives of citizen participation.
\end{abstract}

Keywords: Public Services, Business Process Management, Ciberdemocracy, Electronic Democracy, Conflict Mediation.

Resumo. O uso de Tecnologias da Informação e Comunicação tem se tornado um meio fundamental para que as organizações públicas prestem serviços de qualidade ao cidadão, o aproximando da administração pública. Este trabalho tem como objetivo descrever o Método de Análise de Processos para Aproximação Cidadã (MAPAC), cujo objetivo é apoiar um analista ou especialista em processos a pensar e propor soluções com vista a aproximar e inserir o cidadão nos processos de prestação de serviços públicos. O MAPAC foi avaliado em dois cenários distintos. Um pré-teste foi realizado no Instituto Nacional do Câncer (INCA) e um estudo de caso exploratório, em uma unidade especializada em mediações de conflitos do Tribunal de Justiça do Rio de Janeiro (TJRJ). Os resultados descrevem o potencial de aplicação do método e sua capacidade de apoiar a identificação de alternativas para a aproximação cidadã para os processos de prestação de serviços

Palavras-chave: Prestação de Serviços Públicos, Gestão de Processos de Negócio, Ciberdemocracia, Democracia Eletrônica, Mediação de Conflitos.

Cite as: $\quad$ Pires, E. \& Araújo, R. (2020). MAPAC: Process Analysis for Citizen Approach Method (MAPAC: Um Método de Análise de Processos para Aproximação Cidadã). iSys: Revista Brasileira de Sistemas de Informação (Brazilian Journal of Information Systems), 13(2), 04-33. 


\section{Introdução}

A necessidade de estreitar as relações entre o governo e os cidadãos está cada vez mais presente nas intenções do governo, que busca soluções de melhoria de seus processos de prestação de serviço por meio da participação e inserção do cidadão em assuntos públicos utilizando as Tecnologias da Informação e Comunicação. No Brasil, leis, decretos e normas infraconstitucionais são criados para normatizar as relações entre governo e cidadão, além de aferir e controlar a qualidade dos serviços prestados por estas organizações (BRASIL, 2014a) (BRASIL, 2014b) (BRASIL, 2015) (BRASIL, 2016) (BRASIL, 2017) (BRASIL, 2017).

Para o estreitamento dessas relações não basta apenas criar leis, decretos e normas para aferir e controlar a qualidade dos serviços prestados pelas organizações públicas. O cidadão, que paga os seus impostos e necessita de um serviço público eficiente para resolver um determinado problema, frequentemente não tem acesso ou deixa de procurar um dos serviços ofertados pelo governo. Cita-se como exemplos dessas causas: o processo de atendimento ineficiente, a falta de informação sobre o serviço, a falta de insumos onde é atendido, notícias negativas na mídia que levam o cidadão a não procurar o serviço, demora no atendimento do serviço prestado, falta de servidores para atender o cidadão, entre outros exemplos de amplo conhecimento. Os governos, por outro lado, não importando se a esfera deste governo é federal, estadual ou municipal, buscam formas alternativas e inovadoras, utilizando tecnologias, principalmente, as Tecnologias da Informação e Comunicação para ofertar um serviço de qualidade ao cidadão, o que é conhecido como Governo e Democracia Eletrônica.

É um fato reconhecido pelo Governo Federal a importância das organizações públicas prestarem cada vez mais um melhor serviço à sociedade civil. A recente Lei 13.460 (BRASIL, 2017), sancionada em 26 de junho de 2017, abordando a participação, proteção e defesa dos direitos do usuário dos serviços públicos prestados direta ou indiretamente pela Administração Pública dá ênfase à importância da qualidade na prestação do serviço público pelo governo, assim como, da participação e cobrança do cidadão nesta prestação.

Entende-se que a aproximação do cidadão da organização pública prestadora de serviço deve estar definida na missão institucional. Partindo desta premissa, as organizações públicas deveriam estar preocupadas com a melhor prestação de seus serviços ao cidadão, assim como, procurar obter o melhor desempenho de seus processos para ofertar um serviço de qualidade. Para isto, as organizações precisam estar preocupadas em inserir o cidadão em seus processos e vão necessitar de meios, maneiras e técnicas para fazer a análise dos seus processos para promover a aproximação do cidadão. Entretanto, quais seriam os meios, maneiras e técnicas que as organizações públicas prestadoras de serviço podem utilizar para realizar a análise de um processo com vista a inserir e aproximar o cidadão de seus processos? Esta resposta não foi encontrada em revisão de literatura. Desta forma, a questão a ser tratada neste trabalho procura responder a seguinte questão: como prover um método para análise de processos visando identificar propostas de soluções para aproximação cidadã das organizações públicas prestadoras de serviços?

A proposta deste trabalho de pesquisa tem como enfoque de solução utilizar como base a gestão de processos de negócio (BPM), e, em particular, a atividade de 
análise de processos como contexto para que um analista de processos, possa sistematicamente propor possibilidades de melhorias e inovações para aproximar o cidadão da organização pública. A proposta deste trabalho é propor um método Método de Análise de Processos para Aproximação Cidadã (MAPAC) - que sistematize a análise de um processo de prestação de serviço público e apoie um analista de processos a pensar e propor soluções tecnológicas ou não tecnológicas com vista a aproximar o cidadão deste processo.

A metodologia de pesquisa utilizada neste trabalho foi a construção do MAPAC e sua avaliação em duas etapas em dois cenários distintos de aplicação. A primeira etapa contemplou um pré-teste do MAPAC utilizando a modelagem de processo de um hospital, considerado de grande porte, na especialidade de oncologia da cidade do Rio de Janeiro. A segunda etapa consistiu na realização de um estudo de caso exploratório com participantes de perfis profissionais diferenciados, com a finalidade de explorar a aplicação no processo de mediação de conflitos do Centro Judiciário de Solução de Conflitos e Cidadania do Rio de Janeiro (CEJUSC-Capital), uma unidade especializada do Poder Judiciário.

Os resultados do estudo exploratório demonstraram que o MAPAC é de aplicação viável por especialistas em processos, que a qualidade dos produtos gerados pelo método é satisfatória, e que há evidências de ser eficaz e eficiente ao que se propõe em contextos similares. Foi evidenciada também a dificuldade de sua aplicação quando executado por não especialistas, apesar do grau de satisfação positiva por parte dos participantes (especialistas ou não especialistas).

Este trabalho está organizado em 6 seções, incluindo esta introdução. A seção 2 descreve a fundamentação teórica, que aborda os conceitos de Democracia Eletrônica (DE), Projetos de Soluções para Democracia Eletrônica, BPM, Análise de Processos e seus Habilitadores e os Requisitos para Aproximação Cidadã. A seção 3 comenta os Trabalhos Relacionados. A seção 4 apresenta e descreve o funcionamento do MAPAC. A seção 5 descreve o pré-teste e o estudo de caso realizado para avaliar o MAPAC. A seção 6 apresenta as conclusões.

\section{Fundamentação Teórica}

Para conceber o MAPAC, este trabalho se fundamentou em conceitos das áreas de Democracia Eletrônica (DE) e Gestão de Processos de Negócio - Business Process Management (BPM). A seguir, o leitor terá um resumo dos conceitos e abordagens utilizadas na pesquisa.

\subsection{Democracia Eletrônica}

O termo Democracia Eletrônica (DE) ou e-Democracia ou Democracia Digital é amplamente discutido na literatura. A DE estimula novos processos entre governocidadão e cidadão-cidadão por meio das TIC, além de ampliar a interação social para promover a participação e possibilitar a transparência das ações (ARAUJO et al., 2011). A DE pode ser entendida com um conjunto de discursos, teorizações e experimentações que empregam as Tecnologias da Informação e Comunicação para mediar relações políticas, tendo em vista as possibilidades de participação democrática nos sistemas políticos contemporâneos (ARAUJO et al., 2011) (SILVA, 2005). A Internet se apresenta como um instrumento propulsor ímpar da DE, que permite ampliar a interação 
e o estreitamento das relações entre governo-cidadão com vista a democratizar as discussões dos problemas públicos em um espaço virtual.

No contexto da DE, é importante abordar e discutir as relações que se estabelecem entre governo e cidadão. A comunidade científica identifica diferentes níveis dessa relação de aproximação ARAUJO et al. (2011) SILVA (2005). A Figura 1 apresenta uma possível classificação de níveis de participação e interação cidadãogoverno, utilizada nesta pesquisa, onde a participação e interação do cidadão são ampliadas a cada nível em relação à sua participação em discussões, deliberações e tomadas de decisões. Percebe-se na Figura 1 que à medida que o nível de participação e interação do cidadão é incrementado, incrementa-se também, a qualidade da prestação de serviço, a participação do cidadão nas discussões, deliberações e tomadas de decisões (ARAUJO et al., 2011) (SILVA, 2005).

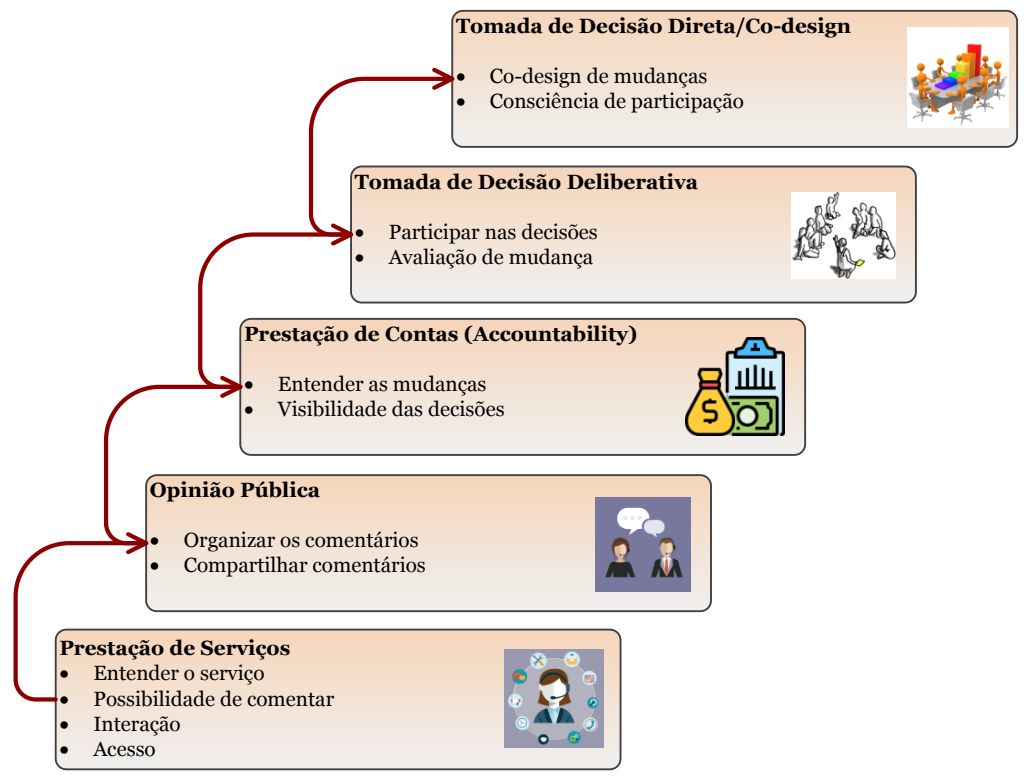

Figura 1 - Níveis/objetivos participação e aproximação cidadã (Fonte: adaptado de (ARAUJO et al., 2011) (Silva, 2005))

Sendo assim, a proposta parte da identificação de cada um dos cinco níveis de participação cidadã nos serviços públicos, onde: no $1^{\circ}$ estágio de participação (prestação de serviços), o governo ou os prestadores de serviços públicos apresentam informações sobre serviços públicos e sua execução, enquanto os cidadãos podem solicitar seu uso sem ter que ir a um órgão governamental necessariamente; no $2^{\circ}$ estágio de participação (coleta de opinião pública:), o governo não coleta apenas as queixas e as dúvidas do cidadão, mas também as sugestões e os pontos de vista sobre o serviço prestado. Assim, objetiva a aumentar a consciência cidadã da opinião pública em relação ao serviço prestado e avaliar a sua qualidade, descrevendo a sua experiência na prestação do serviço prestado; no $3^{\circ}$ estágio de participação (transparência $e$ responsabilidade), a transparência é o foco principal, pois o governo ao dar visibilidade dos atos, das atividades diárias ou decisões, os cidadãos passarão a estar interessados na evolução dos serviços prestados, tendo em vista que o cidadão estará ciente das decisões tomadas e das mudanças realizadas nos serviços ofertados; no $4^{\circ}$ estágio (tomada de decisão deliberativa) os cidadãos expressam as suas opiniões considerando diferentes aspectos de serviços que incluem evolução e mudanças. As participações sobre a priorização de serviços e visibilidade para a sociedade fazem parte deste estágio. No $5^{\circ}$ 
e último estágio, compreende o co-design de serviços públicos, onde o cidadão sugere diretamente as melhorias para definição e implementação dos processos públicos. Os cidadãos passam a ter visão e conscientização da participação de cada ator (cidadão ou governo) e os impactos provocados nas mudanças nos serviços prestados, produzindo a inovação ou co-design destes serviços (ARAUJO et al., 2011) (SILVA, 2005) (ARAUJO; TAHER, 2014).

\subsection{Projetos de Soluções para Aproximação Cidadã}

Outro ponto importante deste trabalho diz respeito a como projetar soluções tecnológicas que apoiem as interações cidadão-governo. A sistematização deste processo de design ainda é uma lacuna na área científica. Diirr et al. (2011), Araujo et al. (2011) e Araujo e Taher (2014), Silva et al. (2016) organizam um conjunto de aspectos ou dimensões da Democracia Eletrônica que podem servir de base para a definição de requisitos e o design de soluções de interação cidadão-governo colaboração, transparência e memória.

\subsubsection{Colaboração}

Magdaleno et al. (2009) identificaram quatros principais aspectos que compõem a interação entre um grupo que podem ocorrer nos processos de negócio de uma organização: a comunicação entre os membros do grupo para troca de informações de forma a superar as distâncias através de canais de comunicação; a coordenação de atividades para garantir que as tarefas sejam executadas conforme esperado, além de evitar tarefas conflitantes e fornecer produtividade ao grupo; o registro da memória do grupo durante a execução/desenvolvimento da atividade colaborativa para preservar tanto o conhecimento formal obtido através da interação entre os membros do grupo (ex.: documentos, artefatos, etc.), quanto o conhecimento informal (ex.: decisões, ideias, comentários), e a lógica através do qual os artefatos foram criados; a percepção ou compreensão da colaboração entre os atores do processo, possibilitando o entendimento das atividades dos outros membros do grupo para contextualizar as suas próprias atividades.

O Modelo de Maturidade de Colaboração (CollabMM) - proposto por Magdaleno et al. (2009), organiza os aspectos de comunicação, coordenação, memória e percepção em 4 níveis de maturidade de colaboração que um processo de negócio pode atingir (Tabela 1). O objetivo é organizar as práticas de colaboração que podem ser inseridas em processos de negócio e apoiar as organizações a analisarem seus processos, estimulando o projeto da colaboração.

\subsubsection{Transparência}

A transparência pode permitir ou melhorar a visão sobre os processos de funcionamento da organização, as informações e o conhecimento dos serviços prestados, facilitar a investigação e aumentar o grau de confiança entre as organizações e a sociedade civil (CAPPELLI, 2009). O framework proposto por Cappelli (2009), denominado de "Degraus de Transparência", foi dividido em 5 (cinco) graus de maturidade que descrevem os objetivos para que as organizações institucionalizem práticas de maturidade de transparência nos seus processos de negócio. A Tabela 2 apresenta um breve resumo das características de cada Grau de Transparência do framework. 
Tabela 1 - Níveis de Colaboração (Fonte: Adaptado de (ARAUJO; MAGDALENO, 2015), (MAGDALENO et al., 2009))

\begin{tabular}{|l|l|}
\hline $\begin{array}{l}\text { Níveis de } \\
\text { Colaboração }\end{array}$ & Definição \\
\hline $\begin{array}{l}\mathbf{1}^{\circ} \text { Nível - } \\
\text { Casual (ad-hoc) }\end{array}$ & $\begin{array}{l}\text { A colaboração não está explícita nos processos de negócio. A colaboração pode acontecer, } \\
\text { mas ainda depende de iniciativa e habilidades individuais, e seu sucesso depende do } \\
\text { relacionamento e / ou afinidade entre as pessoas. }\end{array}$ \\
\hline $\begin{array}{l}\mathbf{2}^{\circ} \text { Nível - } \\
\text { Planejado }\end{array}$ & $\begin{array}{l}\text { Os processos começam a ser modificados e há inclusão de atividades planejadas para a } \\
\text { colaboração. Este planejamento compreende a formalização de grupos, papéis, } \\
\text { responsabilidades e definição de canais de comunicação entre os grupos. }\end{array}$ \\
\hline $\mathbf{3}^{\circ}$ Nível - & $\begin{array}{l}\text { Os membros do grupo já compreendem o processo no qual estão engajados, seus principais } \\
\text { objetivos, conhecem as responsabilidades e como suas atividades estão relacionadas com os } \\
\text { outros para realizar esses objetivos. Os processos encontram-se em um repositório com o } \\
\text { conhecimento compartilhado para armazenar os artefatos do grupo. }\end{array}$ \\
\hline $\begin{array}{l}\mathbf{4}^{\circ} \text { Nível - } \\
\text { Reflexivo }\end{array}$ & $\begin{array}{l}\text { As organizações percebem o valor do conhecimento que está sendo gerado. Considerando a } \\
\text { comunicação, os processos devem ser formalmente concluídos e seus resultados } \\
\text { comunicados. As lições aprendidas podem ser capturadas, os pontos fortes e fracos são } \\
\text { analisados, o sucesso e os desafios são compartilhados, as ideias para melhorias futuras são } \\
\text { coletadas e os resultados dos grupos de trabalho são publicados. Os membros do grupo estão } \\
\text { cientes da maneira pela qual o grupo colabora durante a execução do processo, enquanto o } \\
\text { conhecimento tácito do processo é compartilhado através de ideias, opiniões e experiências, } \\
\text { aumentando assim a memória do grupo. }\end{array}$ \\
\hline
\end{tabular}

Tabela 2 - Graus de transparência e suas características (Fonte: Adaptado de CAPPELLI (2009))

\begin{tabular}{|l|l|}
\hline $\begin{array}{l}\text { Graus de } \\
\text { Transparências }\end{array}$ & Capacidade da Transparência \\
\hline $\begin{array}{l}\text { Grau 1 - } \\
\text { Acessibilidade }\end{array}$ & $\begin{array}{l}\text { Capacidade é identificada através da aferição de práticas que implementam características } \\
\text { de portabilidade, operabilidade, disponibilidade, divulgação e desempenho. }\end{array}$ \\
\hline $\begin{array}{l}\text { Grau 2 - } \\
\text { Usabilidade }\end{array}$ & $\begin{array}{l}\text { Capacidade é identificada através da aferição de práticas que implementam características } \\
\text { de uniformidade, intuitividade, simplicidade, amigabilidade e compreensibilidade. }\end{array}$ \\
\hline $\begin{array}{l}\text { Grau 3 - } \\
\text { Informativo }\end{array}$ & $\begin{array}{l}\text { Capacidade é identificada através da aferição de práticas que implementam características } \\
\text { de clareza, acurácia, completeza, corretude, consistência e integridade. }\end{array}$ \\
\hline $\begin{array}{l}\text { Grau 4 - } \\
\text { Entendimento }\end{array}$ & $\begin{array}{l}\text { Capacidade é identificada através da aferição de práticas que implementam características } \\
\text { de composição, concisão, divisibilidade, dependência, adaptabilidade e extensibilidade. }\end{array}$ \\
\hline $\begin{array}{l}\text { Grau 5 - } \\
\text { Auditabilidade }\end{array}$ & $\begin{array}{l}\text { Capacidade é identificada através da aferição de práticas que implementam características } \\
\text { de explicação, rastreabilidade, verificabilidade, validade e controlabilidade. }\end{array}$ \\
\hline
\end{tabular}

\subsubsection{Memória}

O registro das informações que ocorrem durante as discussões e deliberações de assuntos públicos frequentemente é perdido. As discussões entre o cidadão e Governo para melhorias dos processos e serviços prestados, críticas, sugestões, documentos formais gerados nas organizações, que se traduzem no conhecimento tácito ou explícito, não são preservados (SERRANO, 2010). Organizar, armazenar, recuperar e compartilhar estas informações se faz necessário, pois auxiliam na melhoria das discussões que envolvem a prestação de serviços públicos (DIIRR et al., 2011).

Serrano (2010) propôs um modelo holístico de Gestão de Conhecimento (GC) e uma sistemática de identificação de requisitos de software a partir da análise intencional dos modelos de processos de negócio. O modelo foi dividido em três fases: coleta de expectativas; estabelecimento de um contexto comum e identificação de problemas. Além da proposta do modelo holístico de GC, Serrano e Santos (2007) desenvolveram um roteiro para definir requisitos de GC através dos dados formais e informais de um processo de negócio, organizando e classificando estes dados a fim de propor soluções tecnológicas ou não. $\mathrm{O}$ roteiro foi dividido em quatro atividades com as seguintes 
finalidades, respectivamente: compreender o processo; identificar conhecimentos requeridos e gerados para cada atividade; classificar os conhecimentos identificados e fazer uma avaliação e propor soluções.

\subsection{BPM}

Segundo Dumas et al. (2018) Business Process Management (BPM) ou Gestão de Processos de Negócio, "é o corpo de métodos, técnicas e ferramentas para identificar, descobrir, analisar, redesenhar e executar e monitorar os processos de negócio para otimizar o seu desempenho". Além disso, promove a redução de custo, tempo de execução e as taxas de erro nos processos das organizações que as implementam. Independentemente de a organização ser do setor público ou privado, BPM envolve o gerenciamento e o aprimoramento contínuo de seus processos por meio de atividades contínuas que perfazem o ciclo de vida de BPM (DUMAS et al., 2018) (RACZYŃSKA, 2015).

O ciclo de vida da gestão de processos de negócio compreende atividades a saber: a identificação de processos onde os processos relevantes para análise são identificados e delimitados no contexto da organização; a descoberta de processos, também designada fase de modelagem de processo ou fase AS-IS, onde o processo executado na organização é mapeado e documentado; a análise de processo que compreende a identificação de questões associadas ao processo, os processos são avaliados qualitativamente e quantitativamente em relação ao seu desempenho, deficiências e oportunidades e sugestões para sua melhoria são avaliadas; o redesenho de processo (fase TO-BE), que tem como objetivo projetar mudanças no processo que ajudem a resolver os problemas identificados na fase anterior; a implementação do processo, em que o novo processo é implantado na organização, e por fim, a fase de monitoramento e controle em que o processo em execução é monitorado quanto ao seu desempenho em relação a objetivos estabelecidos.

\subsubsection{Análise de Processos e seus Habilitadores}

Dumas et al. (2018) nos ensina que parte do trabalho de um analista de processo é identificar e documentar os problemas que afligem um processo. A fase de análise é importante neste aspecto, uma vez que o analista de processo não só estará avaliando como os processos de negócio da organização estão operando, como também terá o entendimento comum de como o trabalho é feito (ABPMP, 2013). A análise inicial de um processo deve responder o que está errado com o processo atual (fase AS-IS) e o que será melhor para este processo no futuro (fase TO-BE) (SHARP; MCDERMOTT, 2009).

Segundo nos ensina Sharp e Mcdermott (2009) a análise de um processo engloba três grandes atividades: a primeira atividade que começa com a verificação das questões relacionadas ao processo em si ou dos possíveis problemas do processo por meio da perspectiva de cada stakeholder (parte interessada - cliente, dono do processo, atores, entre outros), baseado mais nas percepções do que em casos concretos; a segunda atividade conduz as perspectivas dos stakeholders quando o analista determina os objetivos a serem articulados para o estado futuro (fase TO-BE); e a terceira atividade que visa a determinar o diferenciador do processo, i.e., que aspecto do processo, acima de todos os outros irá diferenciá-lo das demais alternativas possíveis para o processo. 
Sharp e Mcdermott (2009) argumentam que a análise de processos pode ser guiada com base em habilitadores. Um habilitador de processo "é um aspecto de um processo que permite que ele seja executado corretamente, trazendo desempenho para o processo. Porém, se um habilitador estiver ausente ou for inadequado (inapropriado) é considerado um desabilitador". Sharp e Mcdermott (2009) definem seis habilitadores que atuam em um processo de negócio: workflow que analisa a complexidade da sequência de passos, decisões (que derivam de regras definidas) e transferências realizadas pelos atores de um processo entre o evento inicial e o resultado final deste processo; sistema de informação ou TI que se refere aos sistemas, informação, computadores e outros dispositivos, equipamentos de telecomunicações que apoiam a execução do processo; motivação e medição que abrangem os sistemas de recompensa ou punição, explícitos e implícitos, da organização em que as organizações, pessoas e os processos são medidos e avaliados; recursos humanos que abrange o conhecimento, as habilidades e a experiência da força de trabalho; políticas e regras que tratam das regras e políticas estabelecidas pela empresa para orientar ou restringir os processos, bem como as leis e regulamentos aplicáveis; e infraestrutura cuja finalidade é observar o design do local de trabalho e infraestrutura física onde o processo é executado.

\subsection{Requisitos para Aproximação Cidadã}

Araujo e Taher (2014) propuseram um framework cujo objetivo é identificar os requisitos necessários de participação e interação do cidadão que dariam suporte à construção de Tecnologias da Informação e Comunicação para aproximar cidadão e governo (Figura 2). A proposta entende que os requisitos para o design de uma solução de aproximação cidadão partem da identificação do nível de participação cidadã desejado: (provisão de informações e serviços ( $1^{\circ}$ nível); coleta de opinião pública $\left(2^{\circ}\right.$ nível); transparência e responsabilidade ( $3^{\circ}$ nível); tomada de decisão deliberativa; $e$ tomada de decisão direta e co-design ( $5^{\circ}$ nível).

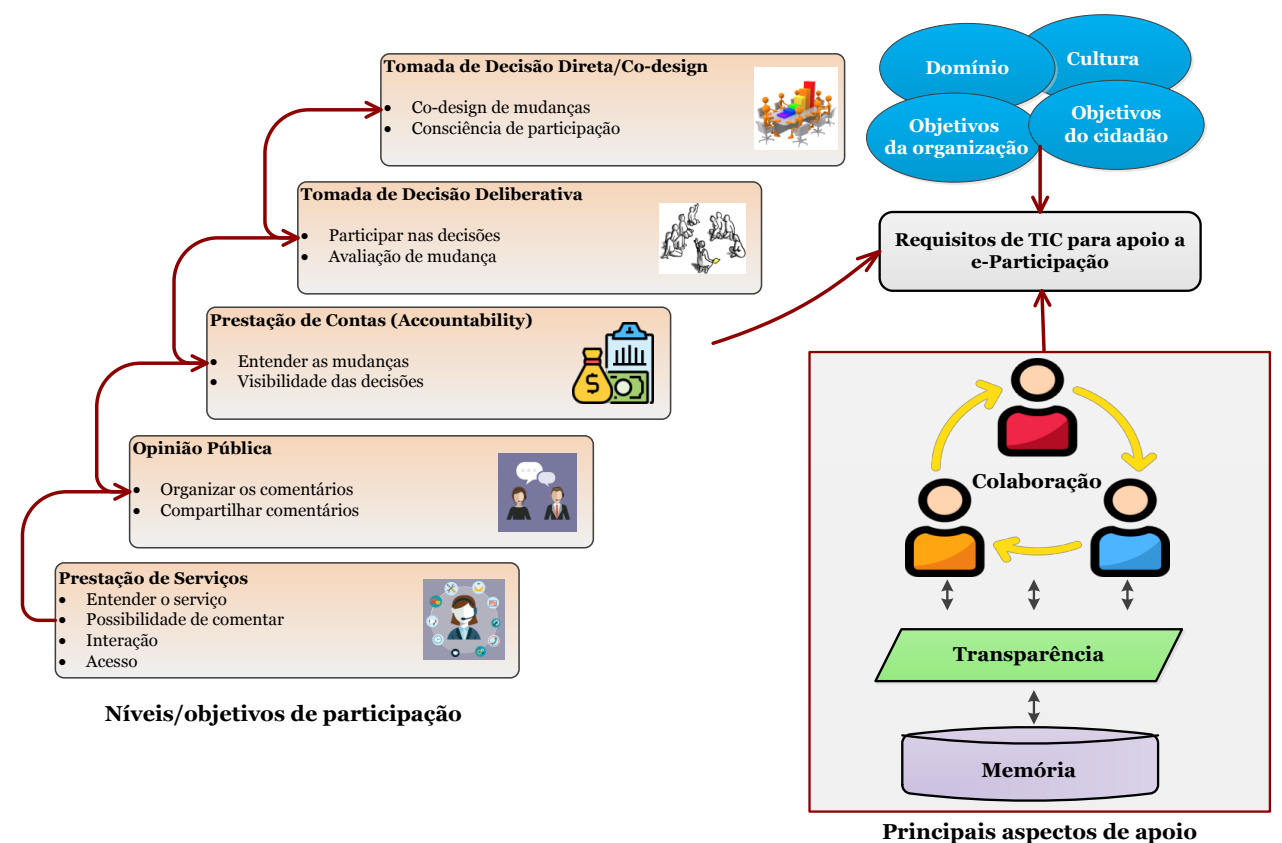

Figura 2. Modelo conceitual para o design de soluções de aproximação cidadã (Adaptado de ARAUJO E TAHER (2014)) 
Para este suporte é preciso levar em consideração os aspectos ortogonais: $d a$ colaboração, da transparência e da memória para cada nível de participação a fím de especificar o conjunto dessas ferramentas. Assim, a visão aprofundada dos requisitos de colaboração, transparência e memória social poderia fornecer aos designers de ferramentas uma fonte de ideias sobre onde classificar o nível de participação de um serviço público específico. Além dos requisitos de identificação do nível de participação cidadã, se faz necessário realizar um estudo de todo o contexto organizacional: domínio em que a organização está inserida, a sua cultura, os seus objetivos, assim como, os objetivos do cidadão. Este levantamento é fundamental, pois, também pode influenciar nos tipos de requisitos para a construção das ferramentas que darão o devido suporte à aproximação do cidadão ao governo (ARAUJO; TAHER, 2014).

\section{Trabalhos Relacionados}

A revisão bibliográfica realizada nesta pesquisa não detectou trabalhos que tratassem especificamente da construção de um método sistematizado específico para aproximar um cidadão dos processos de uma organização pública. No entanto, foram encontrados vários trabalhos que apresentam propostas de modelos para avaliação de iniciativas de participação eletrônica.

Nograšek e Vintar (2015), por exemplo, propuseram uma melhoria do framework cujo objetivo fornecia uma melhor percepção das características de Transformação Organizacional (OT) das organizações do setor público na era do governo eletrônico (e-Governo). Macintosh e Whyte (2008) procuraram investigar e demonstrar o uso de uma gama de perspectivas e métodos para avaliar iniciativas de eParticipação os quais desenvolveram um framework analítico para estas iniciativas. Os autores realizaram um estudo de caso da avaliação da e-Participação para quatro projetos conduzidos pela autoridade local de fluxo "top down" do Projeto Nacional de e-Democracia Local do Reino Unido.

Em relação ao uso da BPM como base para melhoria de processos públicos e/ou participação cidadão. Raczyńska (2015) investiga os problemas relacionados à gestão de processos em organizações públicas da Polônia, decorrentes de barreiras do uso de conceitos modernos de gestão. O autor destaca o modelo de maturidade de processos criado com base na metodologia PRI (Institutional Development Plan - PRI methodology $)^{1}$, utilizado para autoavaliar as condições de funcionamento da gestão de um órgão da administração pública, o que possibilita ao mesmo tempo, fáceis programações de ações de melhorias. Niehaves e Malsch (2009) realizaram uma pesquisa quantitativa na Alemanha, que examinou seis fatores de impacto no envolvimento dos cidadãos em iniciativas de BPM de governo local. A pesquisa mostrou que o envolvimento do cidadão na reforma de processos é motivado pela legitimação dessas reformas por aumentar a satisfação do funcionário público e por explorar o potencial educacional dessas atividades e não pela redução de custos. Um obstáculo encontrado para o envolvimento dos cidadãos é a falta de recursos de pessoal administrativo. Os dados resultantes desse estudo mostraram que o objetivo da participação dos cidadãos em processos de BPM não é necessariamente a redução de

\footnotetext{
${ }^{1}$ http://pri.msap.pl/index.php?option=com_contenteview $=$ articleeid $=49 \mathrm{eItemid}=37$
} 
custos ou de alta eficiência em processos de negócios, mas sim o aumento da legitimidade e proporcionar mútua compreensão dos funcionários públicos e dos cidadãos (NIEHAVES; MALSCH, 2009).

Diversas propostas de design de soluções para aproximar cidadão-governo e fazer com este cidadão compreenda o funcionamento dos processos de negócio de uma organização pública prestadora de serviços, vêm sendo desenvolvidas e aprimoradas ao longo dos anos (ARAUJO; TAHER, 2014), (ENGIEL, 2012), (DIIRR et al., 2010), (TAVARES, 2012), (TAVARES et al., 2014), (SELL; ARAUJO, 2015), (CLASSE, 2017).

Diirr (2011) e Diirr et al. (2014) discorrem a respeito de design de ambientes para aproximação cidadã. Diirr et al. (2010) apresentou uma abordagem baseada em conversas sobre os processos de prestação de serviços públicos para promoção da interação entre cidadãos e prestadores de serviços. Engiel (2012) propôs o projeto de entendimento de modelos de processos de prestação de serviços públicos a partir da elaboração de um modelo de processo inteligível para os cidadãos. Gomes (2011) investigou a utilidade de um sistema de animação de regras em processos de prestação de serviços públicos, por meio da construção de um protótipo do sistema de animação de regras em processos para apoiar a realização de um estudo de caso. A análise dos resultados deste estudo evidenciou que a solução proposta pode ser útil para auxiliar o cidadão na compreensão da forma como um serviço é prestado. Sell (2016) buscou aproximar o cidadão das discussões sobre processos de negócios em organizações públicas utilizando uma linguagem declarativa denominada de Semantics of Business Vocabulary and Business Rules (SBVR). Sell (2016) desenvolveu artefato de protótipo denominado "Regra Clara" que expressava as regras de negócio de um processo de prestação de serviço, promovendo o entendimento, a discussão e o compartilhamento de experiências e informações sobre os serviços ora prestados.

As pesquisas mencionadas acima visaram a melhoria da qualidade dos processos de prestação do serviço público com a finalidade de aproximar o cidadão desses processos. Estas pesquisas tiveram como objetivo o engajamento do cidadão, buscaram a percepção da satisfação do cidadão em relação às organizações públicas e criaram e aplicaram modelos de maturidade para serviços públicos com foco na melhoria da prestação dos serviços prestados. No entanto, dentre os diversos trabalhos analisados, nenhum deles apresentou uma forma sistematizada de análise de um processo público de prestação de serviço com a finalidade de aproximar o cidadão das organizações públicas, que possa ser integrada ao ciclo usual de atividades da gestão de processos de negócio (modelagem, análise, redesenho e implementação do processo). Desta forma, a proposta do MAPAC é sistematizar a análise de um processo de prestação de serviço público para que especialistas possam redesenhar este processo e chegar a soluções com vista a ampliar a aproximação entre cidadãos e os processos de serviços prestados.

\section{Método de Análise de Processos para Aproximação Cidadão - MAPAC}

O MAPAC é um método para ser utilizado durante a fase do ciclo de vida de análise de um processo de prestação de serviço público, tendo como objetivo conduzir sistematicamente um analista de processos a identificar soluções tecnológicas ou não que visem à aproximação do cidadão, usuário deste processo. 
Como foi abordado em seções anteriores, Sharp e Mcdermott (2009) propõem que durante a fase de análise de um processo, o analista faça uso de habilitadores de processos. O MAPAC sugere a inclusão dos aspectos de apoio à Democracia Eletrônica - colaboração, transparência e memória - como habilitadores de processos visando a ampliação da participação cidadã. A Figura 3 apresenta os habilitadores usuais de um processo, propostos por Sharp e Mcdermott (2009), além dos habilitadores de DE que são utilizados no MAPAC. A proposta é fazer o analista de processos pensar em melhorias do processo, habilitando-o, isto é, tornando mais eficientes. Cada caixa dentro da linha pontilhada é um habilitador que pode ser considerado uma atividade a ser executada pelo analista de processo, independente da ordem de análise deste habilitador.

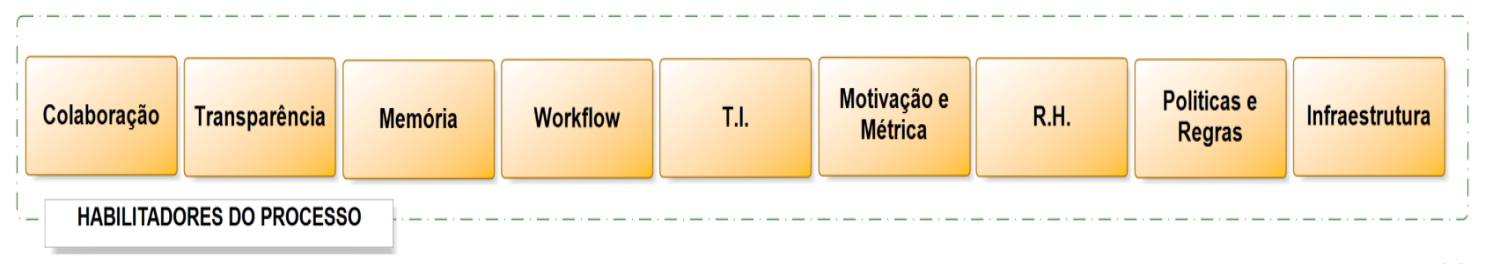

Figura 3. Habilitadores de processos para aproximação cidadã

O MAPAC também se baseia no conceito de níveis de participação cidadã - $1^{\circ}$ nível-prestação de serviço, $2^{\circ}$ nível-coleta de opinião, $3^{\circ}$ nível-prestação de contas, $4^{\circ}$ nível-democracia deliberativa e $5^{\circ}$ nível-democracia direta (ARAUJO et al., 2011) (ARAUJO; TAHER, 2014) (SILVA, 2005) - cuja organização pública prestadora de serviço deseja para os seus processos de negócio. As propostas de soluções tecnológicas ou não tecnológicas precisam atender a estes níveis de participação e interação do cidadão desejado pela organização nos seus processos de prestação de serviço.

O método define um conjunto de etapas que auxiliam o analista de processos a realizar a análise de um processo de prestação de serviço público com base nos habilitadores de processos, com vistas a criar soluções que levem o processo a alcançar um nível de participação desejado.

\subsection{Etapas do MAPAC}

O método está dividido em 3 (três) etapas (Figura 4) e cada uma das etapas prevê a execução de atividades, resumidas nas seções que se seguem. Uma descrição detalhada das atividades, instrumentos de execução e modelos de documentação do MAPAC podem ser obtidos em (PIRES, 2017).

A primeira etapa do MAPAC (Figura 5), analisar contexto do processo organizacional, possui a finalidade de sugerir ao analista o entendimento do contexto onde os processos da organização pública funcionam. Esta análise visa auxiliar o analista a identificar as principais questões que envolvem a prestação do serviço, aspectos relevantes da cultura organizacional, os stakeholders dos processos, quais os limites (fronteiras) de atuação da organização e qual a sua estratégia e expectativa para promover a participação cidadã. Além disso, o analista de processos define os níveis de participação desejados pela organização pública com intuito de nortear as soluções durante a execução da análise dos processos pelo analista. Nesta fase, o analista se preocupa também identificar as leis e as normas vigentes que se impõem ao processo atual e que poderão impactar nas futuras propostas de soluções. Mesmo sendo uma fase 
preliminar de análise, esta etapa propicia ao analista organizar as informações necessárias para tomada de decisão mais assertivas a respeito de soluções para o processo de prestação de serviço ao longo da execução do método.

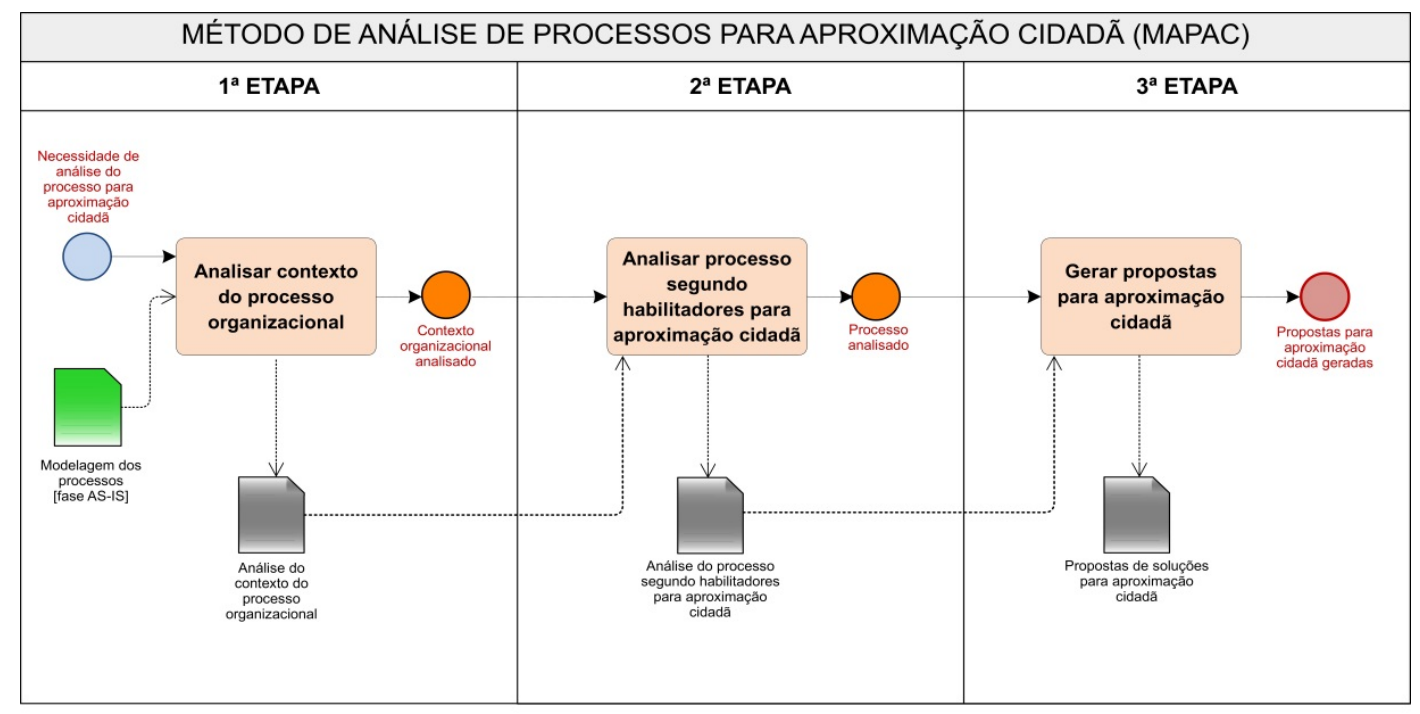

Figura 4. Visão Geral do MAPAC

Na Figura 5, a etapa se inicia sempre que há a motivação da organização para promover a aproximação do cidadão em um ou mais processos de prestação de serviço. Como entrada desta etapa, o analista deve possuir a modelagem dos processos atuais (fase AS-IS) a qual já tenha sido realizada pela organização, tratando-se então de uma premissa para que o MAPAC possa ser executado. Ao final da execução desta primeira etapa do MAPAC, as informações colhidas do contexto do processo de prestação de serviço da organização e a definição dos níveis de participação cidadã desejados estarão registradas no documento de Análise do Contexto do Processo Organizacional, que servirá de insumo para a $2^{\mathrm{a}}$ etapa.

A Figura 6 apresenta a segunda etapa do MAPAC (Figura 6), analisar o processo segundo os habilitadores para aproximação cidadã. Nesta etapa, o analista de processos é instruído a realizar análise do processo por meio do conjunto de habilitadores previstos pelo método. Para que o analista de processos possa pensar em soluções ou descobrir novos problemas que afetam o processo atual da organização em relação à aproximação cidadão, foi elaborado um conjunto de questões que facilitem a reflexão a respeito dos habilitadores (Tabelas 7, 8, 9, 10,11, 12, 13, 14 e 15 do anexo). As soluções e questões relacionadas à participação cidadão no processo surgem à medida que o analista começa a questionar e se aprofundar na análise do processo atual (fase AS-IS) da organização, havendo a necessidade de investigar estes problemas, analisar as suas causas, identificar os impactos no processo e propor sugestões de melhorias. $\mathrm{O}$ analista de processos identifica problemas e busca propostas de soluções com o auxílio dos stakeholders, realizando a análise do processo tanto os aspectos da democracia eletrônica como atividades a serem executadas, apoiados pelos habilitadores de processos. Espera-se como resultado para esta etapa que o processo esteja analisado 
sob os aspectos ou dimensões de Democracia Eletrônica de colaboração, memória e transparência e as soluções apontadas estejam aderentes aos objetivos estratégicos da organização, além de referenciadas pelos níveis de participação desejados, possibilitando assim, suprir os objetivos da organização na busca de melhorias do processo de serviço. Ao final da execução as informações geradas são registradas no documento de Análise do Processo Segundo os Habilitadores para Aproximação Cidadã pelo analista de processos que servirá de insumo para a próxima etapa.

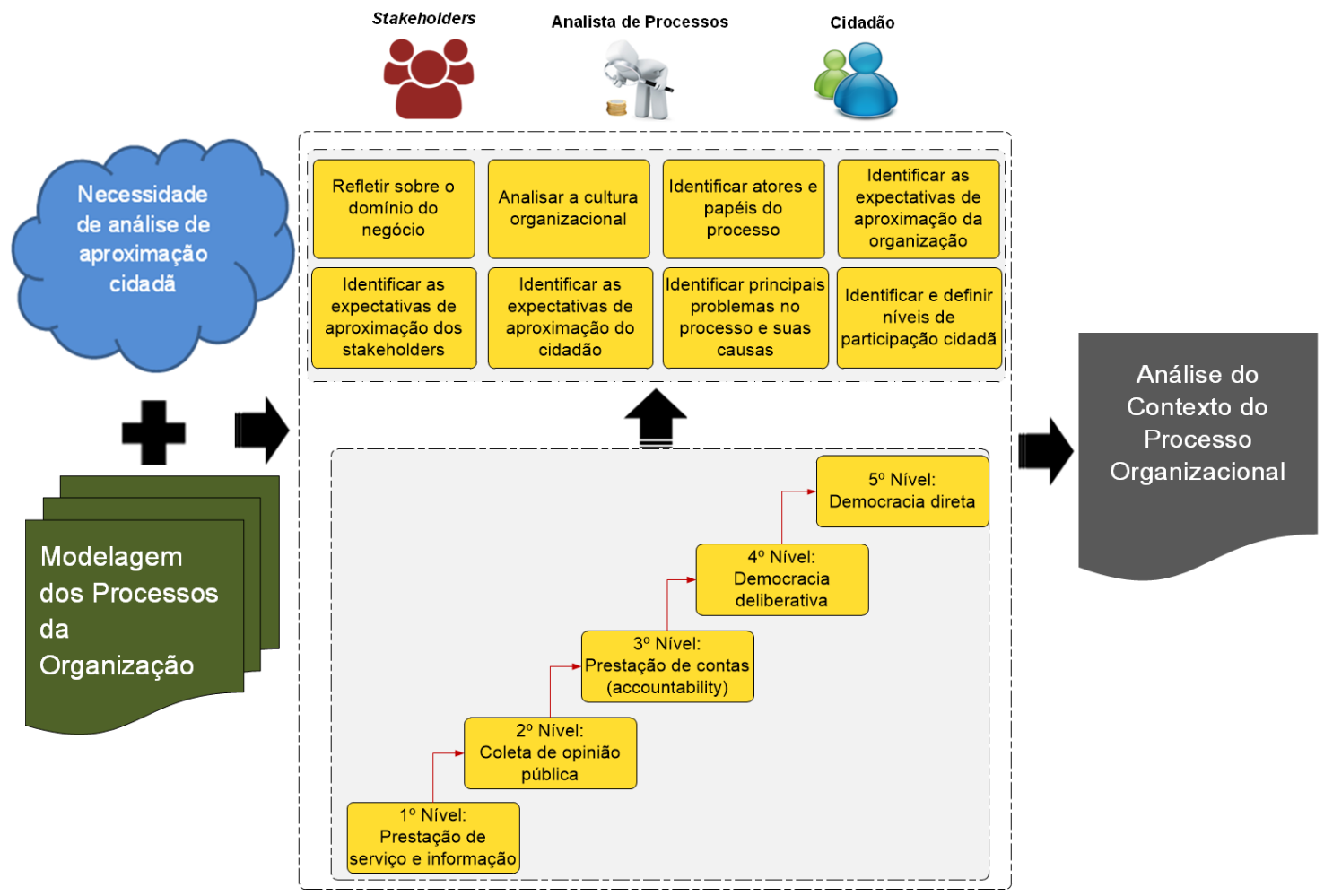

Figura 5. Visão das atividades da $1^{a}$ Etapa: Analisar Contexto do Processo Organizacional

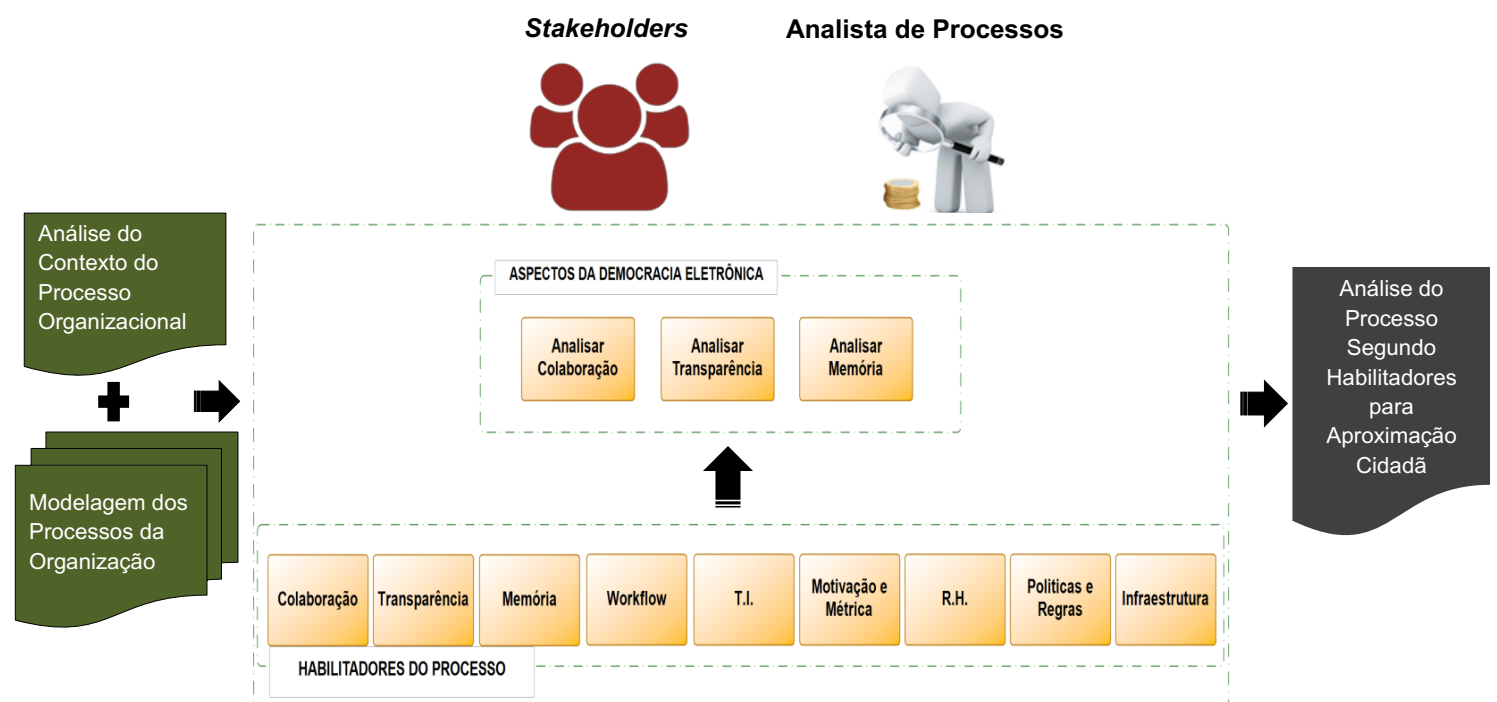

Figura 6. Visão das atividades da $2^{\mathrm{a}}$ Etapa: Analisar Processo Segundo Habilitadores para Aproximação Cidadã [fase AS-IS] 
Na terceira etapa (Figura 7), gerar propostas de soluções para aproximação cidadã, o analista de processos de posse das informações obtidas nas etapas anteriores, aponta as propostas de soluções para aproximação cidadã. Para cada proposta identificada pelo analista de processos haverá a necessidade de justificá-la. Em seguida o analista deve destacar os impactos nas operações diárias, os impactos na estrutura do processo e os benefícios esperados por essa proposta de aproximação cidadã, além da sua priorização e estimativa de custos e prazos para implantação.

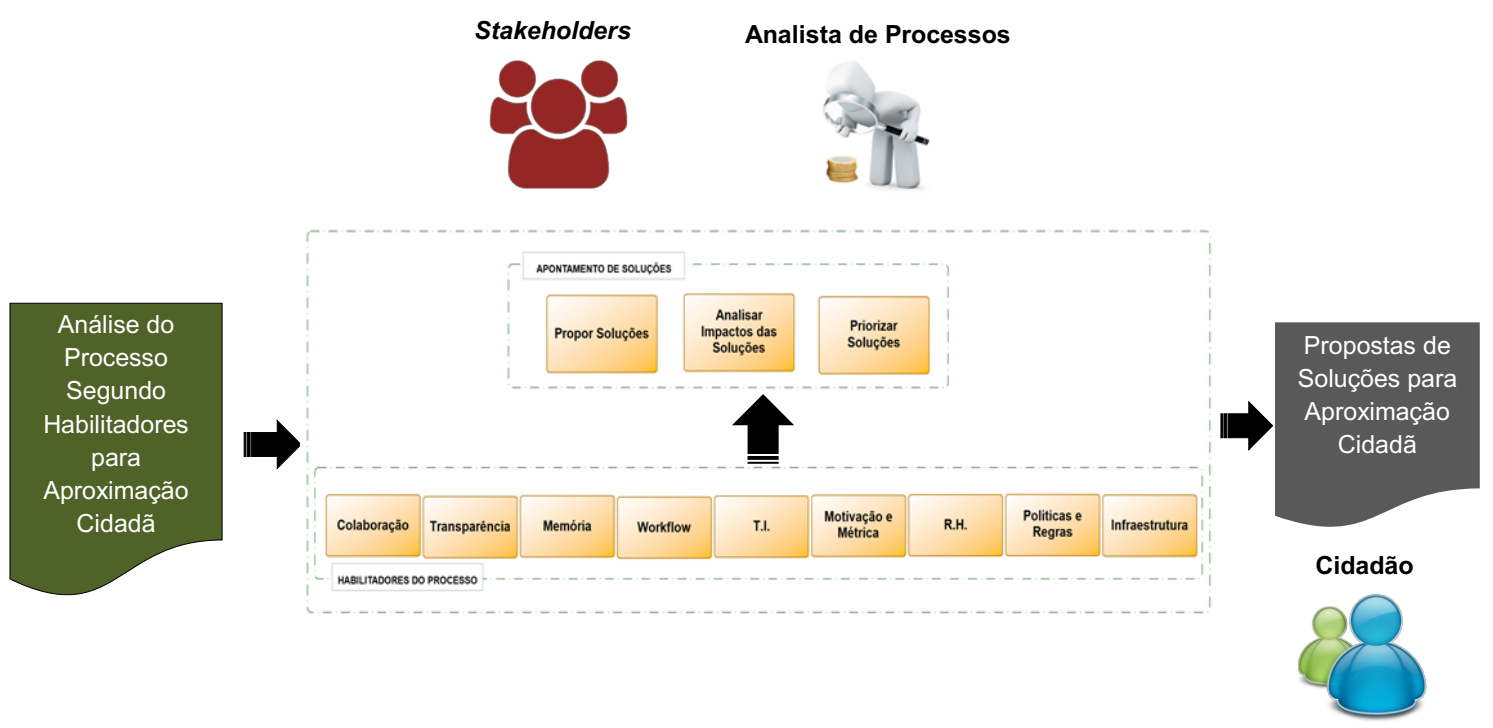

Figura 7. Visão das atividades da $3^{\mathrm{a}}$ Etapa: Gerar Propostas de Soluções para Aproximação Cidadã

As soluções identificadas são registradas no documento de Propostas de Soluções para Aproximação Cidadã a fim de possibilitar a organização escolher as soluções que tragam valor para o cidadão, para os colaboradores e para os seus processos.

Entende-se que ao final da execução desta etapa, o analista estará provendo à organização e aos stakeholders a oportunidade de implantar alterações em seus processos. $\mathrm{O}$ analista deve avaliar o levantamento realizado quanto ao contexto da organização para ponderar se as propostas de soluções apresentadas irão impactar a cultura organizacional. Além disso, deve observar se estas propostas de soluções estão atendo as expectativas almejadas pelo cidadão em relação ao processo de prestação de serviço da organização, dando maior peso às suas expectativas em relação às melhorias. Desta forma, o analista estará direcionando a organização para cumprimento da sua missão e visão institucionais e gerando valor não para o processo apenas e sim, para toda a organização e sua cadeia de valor que inclui os colaboradores internos e externos, fornecedores, governo e principalmente o cidadão que deseja um serviço de qualidade.

\section{Avaliação}

A avaliação do método foi realizada em duas etapas. A primeira etapa contemplou um pré-teste (YIN, 2015) para ajustes do MAPAC, tendo como contexto o processo de 
agendamento de cirurgias em um hospital público especializado no tratamento do câncer, o Instituto Nacional do Câncer (INCA). A avaliação compreendeu a execução do MAPAC com dois participantes: o próprio pesquisador como analista do processo e um gestor (demandante do projeto) para validar as informações geradas pela execução do MAPAC. Esta execução indicou a necessidade de realizar os seguintes ajustes no MAPAC: i) inclusão da atividade "identificar as expectativas de aproximação do cidadão" ( $1^{\text {a }}$ etapa do MAPAC) para avaliar a real necessidade da mudança do processo, sob a ótica do cidadão, i.e., a percepção de como o processo de prestação de serviço é visto; ii) alterações, eliminações e inclusões de diversas questões para análise dos habilitadores de colaboração, transparência e memória ( $2^{\mathrm{a}}$ etapa do MAPAC), com intuito de facilitar o analista de processos a pensar em soluções ou identificar novos problemas que estivessem afetando o processo; iii) alteração no modelo de documentação para a $3^{\text {a }}$ etapa do método, com a inclusão do campo "justificativas" das propostas de solução.

Em seguida, as soluções de aproximação cidadã geradas pela execução do MAPAC foram apresentadas ao gestor do processo o qual foi solicitado que respondesse um questionário de avaliação com as seguintes questões: Q1) Qual a qualidade das informações geradas pelo método para uma tomada de decisão por parte da organização? Avaliação da percepção de relevância, completude, clareza, utilidade e grau de satisfação em relação às informações geradas; e Q2) Quais os aspectos positivos e negativos apresentados pelos artefatos (documentos) MAPAC?

Os resultados reportados pelo stakeholder apontaram para a utilidade, a relevância, a completude e a satisfação com as informações prestadas pelo método, bem como permitiram aperfeiçoar os modelos de documentação do método, facilitando seu uso. O stakeholder apontou também a dificuldade de entendimento dos resultados por parte de profissionais não acostumados com a modelagem e análise de processos.

A segunda avaliação contemplou um estudo de caso exploratório (YIN, 2015) com a finalidade de explorar a aplicação do MAPAC no contexto do processo de mediação de conflitos (fase pré-processual), de uma unidade especializada do Tribunal de Justiça do Rio de Janeiro (TJRJ), o Centro Judiciário de Solução de Conflitos e Cidadania do Rio de Janeiro (CEJUSC-Capital). O objetivo de um estudo de caso, conforme mencionado por Yin (2015) e Antonio, Fornazin e Araujo (2018), é descrever "como" e/ou "porque" um determinado fenômeno acontece em um determinado contexto, sem a exigência de controle por parte do pesquisador. Um estudo de caso exploratório é ainda aquele onde se procura observar variáveis importantes que ajudem a descrever como o fenômeno de interesse ocorre em um contexto, mesmo que ainda sem a possibilidade da teorização a partir de seus resultados. As evidências do estudo de caso foram obtidas por meio de observação direta, técnica de triangulação de dados, análise documental e entrevistas com os principais atores do CEJUSC-Capital, além de

aplicações de questionários aos participantes das unidades de caso. A seguir é apresentado o processo do CEJUSC-Capital.

\subsection{Contexto do Estudo de Caso}

O Centro Judiciário de Solução de Conflitos e Cidadania do Rio de Janeiro (CEJUSCCapital) é uma unidade especializada do Poder Judiciário (TJRJ) no atendimento ao cidadão para a solução consensual de conflitos e orientações nas matérias relativas à 
cidadania. O CEJUSC-Capital não possuía os seus processos de prestação de serviços modelados e documentados o qual se precisou realizar este trabalho. Todo o processo de mediação pré-processual foi modelado para que pudesse ser submetido ao estudo de caso como um artefato de entrada para execução do MAPAC.

O processo de mediação pré-processual tem como objetivo realizar uma sessão de mediação em um dos CEJUSC do estado do RJ, onde as partes possam solucionar os seus conflitos. O processo compreende as etapas de agendamento as quais o cidadão busca estes centros de mediação, passando pelas etapas intermediárias que antecedem a programação da agenda de mediações até a sessão de mediação propriamente dita e conclui com o Termo de Sessão de Mediação (TSM) entregue ao cidadão o qual é considerado um título executivo extrajudicial, conforme o artigo 515 do novo Código de Processo Civil de 2015 (BRASIL, 2015).

O processo da mediação se inicia quando há um conflito e o cidadão busca um meio alternativo para se chegar a um acordo com a outra parte do conflito. Então, o cidadão procura acesso aos CEJUSC-RJ para que o auxilie na tentativa de agendar uma mediação. Há três formas distintas para solicitar uma mediação: a primeira forma de acesso, através do site do Tribunal de Justiça RJ (TJ-RJ); a segunda forma, o cidadão vai diretamente ao CEJUSC-Capital, onde preenche uma ficha denominada FIAM (Formulário de Inscrição e Acompanhamento de Mediação); e a terceira, através de email enviado a própria secretaria do CEJUSC-Capital.

Após a secretaria tomar ciência da solicitação, começa o processo de agendamento e convocação, via envio de uma carta-convite, para que as partes compareçam no dia e hora agendados para a sessão de mediação. Em seguida, um mediador é convidado para participar da sessão de mediação cuja seleção é baseada em critérios de competência no assunto a ser mediado. Quando as partes comparecem, na data e hora determinadas, são encaminhadas pelo (a) recepcionista (colaborador (a) da secretaria do CEJUSC-Capital) para sessão de mediação. As partes são recebidas pelo mediador que dá início a explicação de como funciona a sessão de mediação. $O$ mediador, através de técnicas de mediação de conflitos, busca o consenso entre as partes. O resultado da mediação pode levar a um acordo parcial, acordo total, acordo provisório ou sem acordo. No caso de um acordo parcial ou provisório, as partes podem retornar para uma nova sessão de mediação. No caso da sessão de mediação finalizar com acordo ou sem acordo ou com um acordo provisório entre as partes, o fluxo segue normalmente e é gerado o Termo de Sessão de Mediação (TSM) cuja denominação é "acordo total". Pode haver a possibilidade de uma das partes ou ambas faltarem a sessão de mediação. $\mathrm{O}$ mediador pode também viabilizar uma nova sessão de mediação, caso a parte que compareceu aceite.

Há situações em que o conflito pode tratar de assuntos de menores de idade (16 anos) ou um cidadão acima de 65 anos o que envolve a atuação do Ministério Público (MP) para a homologação do acordo. Pode haver, também, a necessidade das partes, após a sessão de mediação, solicitarem a homologação do acordo junto ao MP. Todos os TSM redigidos pelos mediadores, com acordo ou não, são enviados para a secretaria do CEJUSC-Capital, que serão analisados pelo colaborador (a) do dia ou pela secretária responsável pelas mediações pré-processuais para dar prosseguimento ao processo.

Após a análise do TSM pela secretaria, este setor pode tomar as seguintes decisões: reagendar ou remarcar uma mediação; encaminhar o processo ao coordenador 
(a) do CEJUSC-Capital para solicitar vista (solicitação de posicionamento) ao Ministério Público (MP) ou finalizar o processo. Em todos os casos o processo é digitalizado, finalizado (baixado) no sistema de apoio DCP e posteriormente arquivado.

$\mathrm{Na}$ situação em que o coordenador (a) abre vista ao MP e o processo retorna sem a necessidade de cumprimento de exigência, o juiz do CEJUSC-Capital atua, assinando digitalmente (eletronicamente) no sistema DCP para finalizar o processo. O juiz avalia os processos quando as partes solicitam a homologação. A seguir a execução do estudo de caso com os seus respectivos resultados.

\subsection{Execução do Estudo de Caso}

O estudo de caso teve o seu objetivo apresentado de acordo com o paradigma GQM (Goal Question Metric) (BASILI et al., 2002) para:

Analisar a execução do MAPAC em um modelo de processo de prestação de serviço público

Com o propósito de explorar a viabilidade, a qualidade dos produtos gerados pelo método e a satisfação dos participantes

Com respeito às características das informações geradas quanto à relevância, completude, objetividade e utilidade, além dos aspectos positivos e negativos com os resultados obtidos pela execução do MAPAC

Do ponto de vista de um gestor e analistas de processos de negócio

No contexto de um ambiente real de uma unidade especializada do Poder Judiciário (CEJUSC-Capital)

Para que se pudesse explorar a execução do MAPAC quanto à relevância, completude, objetividade e utilidade, além dos aspectos positivos e negativos apresentados pelos participantes por meio dos dados colhidos durante a execução do método. $\mathrm{O}$ estudo de caso contou com a participação de dois especialistas com perfis profissionais distintos- um colaborador do próprio Tribunal de Justiça RJ (TJRJ) com experiência na área de gestão e um pesquisador e profissional com experiência prática nas áreas de Democracia Eletrônica e BPM. O número de participantes não prejudica a validade do estudo de caso, uma vez que o objetivo do mesmo é observar a execução do MAPAC em seu contexto e para efeito de sua execução é suficiente contar com um analista de processos - responsável pela análise do processo segundo o MAPAC - e um gestor organizacional - responsável por avaliar as sugestões e oportunidades apresentadas como resultado da aplicação do método.

Foi aplicado um questionário, antes da realização do estudo para verificar a formação acadêmica e experiência profissional relacionada às habilidades que envolvem BPM, DE, participação cidadã, colaboração, transparência e memória. O grau e o tempo de experiência apresentado pelo $1^{\circ}$ participante na área de gestão foram um dos fatores a ser considerado no estudo, pois evidenciou a sua experiência na área de gestão como coordenador do CEJUSC-Capital. Apesar de pouco tempo de atuação no CEJUSCCapital, o participante apresentou um bom conhecimento dos processos que envolvem a mediação de conflitos. Além disso, o participante destacou os aspectos de colaboração e transparência como tendo sidos usados em projetos pessoais e na indústria, sendo que o aspecto de memória nunca foi utilizado. $\mathrm{O} 2^{\circ}$ participante destacou que possui bons 
conhecimentos nas áreas de BPM, DE e participação cidadã, com 12 anos de experiência, inclusive utilizados em projetos na indústria. Ao final das atividades, os participantes preencheram o questionário para coleta das evidências e análise dos dados. O processo analisado no estudo de caso foi considerado de média complexidade.

A avaliação foi organizada em 3 (três) questões e para cada questão foram apresentadas e avaliadas as variáveis dependentes. Para cada questão (Q1, Q2 e Q3), são apresentados a seguir os resultados obtidos durante os estudos para cada participante. Ao final são apresentadas as conclusões para cada uma das questões em relação ao MAPAC.

Q1 - Qual é a viabilidade de execução do MAPAC? Para verificar essa questão, observam-se as evidências baseadas nas seguintes variáveis criadas para esta finalidade: eficácia - a capacidade de os participantes concluírem todas as etapas propostas pelo MAPAC utilizando os instrumentos para sua execução; eficiência avaliação do tempo total que os participantes levam para execução do MAPAC; e a dificuldade - análise das dificuldades apresentadas pelos participantes durante a execução de cada etapa do MAPAC. Para verificar a eficiência, a evidência foi obtida por meio da coleta do tempo de execução de cada uma das etapas do método, além da análise das informações geradas pelos participantes. Para analisar as dificuldades apresentadas, as informações foram coletadas através da aplicação de um questionário de avaliação do estudo de caso. A Tabela 3 resume os resultados obtidos para Q1. Cada coluna está representada por participante (Gestor do CEJUSC-Capital e o Pesquisador).

\section{Tabela 3. Apresentação e discussão dos resultados para Q1}

\begin{tabular}{|c|c|c|}
\hline & $\begin{array}{l}1^{\circ} \text { Participante - Gestor do } \\
\text { CEJUSC }\end{array}$ & $\begin{array}{l}2^{\circ} \text { Participante - Pesquisador em BPM e } \\
\text { DE }\end{array}$ \\
\hline Eficácia & $\begin{array}{l}\text { Concluiu a execução de todas as } \\
\text { etapas propostas, apesar do } \\
\text { participante nunca ter trabalhado com } \\
\text { Os conceitos das disciplinas de BPM e } \\
\text { DE. A maioria das propostas de } \\
\text { soluções apresentadas pelo gestor } \\
\text { tendeu para as soluções não } \\
\text { tecnológicas. }\end{array}$ & $\begin{array}{l}\text { Concluiu a execução de todas as etapas } \\
\text { propostas. Possui bons conhecimentos de BPM e } \\
\text { DE o que contribui para a conclusão de todas as } \\
\text { atividades com certa facilidade. O participante teve } \\
\text { dúvidas quanto a execução do processo, pois } \\
\text { apenas teve o modelo de processo para executar o } \\
\text { processo, sem a vivência do ambiente. }\end{array}$ \\
\hline Eficiência & $\begin{array}{l}\text { Concluiu os trabalhos com um tempo } \\
\text { total de } 13 \mathrm{~h} 47 \mathrm{~min} \text { em } 4 \text { (quatro) } \\
\text { sessões. O gestor não dispunha de } \\
\text { tempo para realizar em uma única } \\
\text { cessão. Há evidências que este tempo } \\
\text { de execução poderia ter sido de } 7 \mathrm{~h} \text {, } \\
\text { porém, o tempo total de } 13 \mathrm{~h} 47 \text { min não } \\
\text { implicou em falta de eficiência, devido } \\
\text { à complexidade do processo e os } \\
\text { conhecimentos dos conceitos } \\
\text { necessários para execução do } \\
\text { método. }\end{array}$ & $\begin{array}{l}\text { Concluiu os trabalhos em } 4 \text { h } 20 \text { min em } 1 \text { sessão. O } \\
\text { conhecimento das disciplinas de BPM e DE foram } \\
\text { favoráveis para o participante executar todas } \\
\text { atividades. Além disso, a disponibilidade de tempo } \\
\text { do participante para participar do estudo de caso. }\end{array}$ \\
\hline Dificuldade & $\begin{array}{l}\text { Apresentou dificuldades relacionadas } \\
\text { aos conceitos de BPM, DE e } \\
\text { habilitadores de processos, além de } \\
\text { relacionar o contexto do CEJUSC- } \\
\text { Capital aos aspectos ou dimensões de } \\
\text { colaboração, transparência e e } \\
\text { memória. Destaca-se que o } \\
\text { participante teve dificuldade de } \\
\text { apontar os impactos sobre a } \\
\text { organização que as novas propostas } \\
\text { de soluções poderiam ocasionar. }\end{array}$ & $\begin{array}{l}\text { O participante não apresentou dificuldade, } \\
\text { considerou o MAPAC de fácil aplicação, porém } \\
\text { havendo a necessidade de conhecimentos prévios } \\
\text { de BPM e de habilitadores de processos para sua } \\
\text { execução. }\end{array}$ \\
\hline
\end{tabular}


Q2 - Qual a satisfação dos participantes quanto à execução do MAPAC? Para verificar essa questão foram observadas as evidências baseadas nas seguintes variáveis criadas para esta finalidade: satisfação - a satisfação dos participantes quanto aos resultados gerados pela execução do MAPAC; aspectos positivos - destaques dos pontos positivos relatados pelos participantes ao final da execução do MAPAC; aspectos negativos - destaques dos pontos negativos relatados pelos participantes ao final da execução do MAPAC. As informações foram coletadas por meio da aplicação do questionário de avaliação do estudo de caso do método ao final da execução do experimento. A Tabela 4 traz a análise dos resultados obtidos para Q2 de ambos participantes.

Tabela 4. Apresentação e discussão dos resultados para Q2

\begin{tabular}{|c|c|c|}
\hline & $\begin{array}{l}1^{\circ} \text { Participante - Gestor do } \\
\text { CEJUSC }\end{array}$ & $\begin{array}{l}2^{\circ} \text { Participante - Pesquisador em BPM e } \\
\text { DE }\end{array}$ \\
\hline Satisfação & $\begin{array}{l}\text { Apontou que ficou muito satisfeito com } \\
\text { as informações geradas pela execução } \\
\text { do MAPAC, sem tecer novos } \\
\text { comentários. }\end{array}$ & $\begin{array}{l}\text { Relata que ficou muito satisfeito. Comenta que o } \\
\text { MAPAC "permite um pensar sistematizado sobre a } \\
\text { aproximaç̧ão cidadã, porém se executado em } \\
\text { conjunto com a equipe técnica e de negócio, pode } \\
\text { trazer benefícios para organização interessadas no } \\
\text { tema. Ressalva a interação entre as equipes (de } \\
\text { processos e de gestão) de forma que a análise } \\
\text { seja mais ampla possível e que possíveis dúvidas } \\
\text { consigam ser sanadas". }\end{array}$ \\
\hline $\begin{array}{l}\text { Aspectos } \\
\text { positivos }\end{array}$ & $\begin{array}{l}\text { Destacou que o MAPAC confere } \\
\text { "entendimento e a reflexão sobre } \\
\text { processo o processo da organização". }\end{array}$ & $\begin{array}{l}\text { Apontou dois aspectos positivos na execução do } \\
\text { MAPAC: "a sistematização para análise e a } \\
\text { ilustração de uso para cada ponto analisado". }\end{array}$ \\
\hline $\begin{array}{l}\text { Aspectos } \\
\text { negativos }\end{array}$ & $\begin{array}{l}\text { Destacou que a execução do método é } \\
\text { demorada. Fato já previsível, devido à } \\
\text { falta de conhecimento do participante } \\
\text { dos conceitos utilizados na concepção } \\
\text { do MAPAC. }\end{array}$ & $\begin{array}{l}\text { Relata que "o nível de detalhamento pode dificultar } \\
\text { a aplicação do MAPAC por uma equipe de } \\
\text { negócio". Relacionado ao fato "das dificuldades } \\
\text { que a equipe puramente técnica pode enfrentar no } \\
\text { dia-a-dia da prestação de serviços". Acredita-se } \\
\text { realmente que a análise de um processo se torna } \\
\text { muito incipiente e difícil quando realizada por } \\
\text { artefatos (documentações), sem vivenciar/avaliar } \\
\text { as dificuldades de execução do processo e } \\
\text { conversar com os atores que executam o } \\
\text { processo. }\end{array}$ \\
\hline
\end{tabular}

Q3 - Qual a qualidade das informações geradas pela execução do MAPAC? Para verificar estes aspectos foram utilizadas as seguintes variáveis: relevância - se as informações têm impacto na tomada de decisões daqueles que possam utilizá-las; completude - se as informações são apresentadas de forma completas em relação ao processo de prestação de serviço da organização ora analisado; objetividade - se as informações são apresentadas de forma clara, objetiva e de fácil entendimento; utilidade - se as propostas de soluções para aproximação cidadã tem utilidade para o processo de prestação de serviço da organização. A análise das evidências foi realizada pelo pesquisador por meio das informações geradas pelos participantes no estudo de caso através dos instrumentos para execução do MAPAC. A Tabela 5 traz a análise dos resultados obtidos para Q3 de ambos participantes. 
Tabela 5. Apresentação e discussão dos resultados para Q3

\begin{tabular}{|c|c|c|}
\hline & $\begin{array}{l}1^{\circ} \text { Participante - Gestor do } \\
\text { CEJUSC }\end{array}$ & $\begin{array}{l}2^{\circ} \text { Participante - Pesquisador em BPM e } \\
\text { DE }\end{array}$ \\
\hline Relevância & $\begin{array}{l}\text { Evidenciados que as informações têm } \\
\text { relevância, tendo em vista que os } \\
\text { problemas e as soluções apontados } \\
\text { podem suprir a necessidade da } \\
\text { organização. }\end{array}$ & $\begin{array}{l}\text { Evidenciado que as informações têm relevância. } \\
\text { Da mesma forma, os problemas e as soluções } \\
\text { apontados podem auxiliar a organização na } \\
\text { melhoria do processo. As informações geradas } \\
\text { quanto a cultura da organização foi apresentada } \\
\text { de forma apropriada sob os aspectos de DE, } \\
\text { assim como, as propostas de soluções } \\
\text { tecnológicas ou não tecnológicas. }\end{array}$ \\
\hline Completude & $\begin{array}{l}\text { Evidenciado que nem todas as } \\
\text { informações são apresentadas de } \\
\text { forma completa. }\end{array}$ & $\begin{array}{l}\text { Evidenciado que nem todas as informações são } \\
\text { apresentadas de forma completa o que } \\
\text { dificultaria um gestor na tomada de decisão. } \\
\text { Também o participante não apresentou as } \\
\text { justificativas para algumas propostas de } \\
\text { soluções, por falta de atenção, porém não foir } \\
\text { evidenciada a falta de completude. }\end{array}$ \\
\hline Objetividade & $\begin{array}{l}\text { Evidenciado que a maioria das } \\
\text { informações foi apresentada de forma } \\
\text { clara, objetiva, porém não sendo fácil } \\
\text { o entendimento de algumas } \\
\text { informações por falta de } \\
\text { detalhamento. }\end{array}$ & $\begin{array}{l}\text { Evidenciado que todas as informações são } \\
\text { apresentadas de forma claras, objetivas e de fácil } \\
\text { entendimento. }\end{array}$ \\
\hline Utilidade & $\begin{array}{l}\text { Evidenciado que nem todas as } \\
\text { propostas de soluções tiveram o foco } \\
\text { na aproximação cidadã e sim para os } \\
\text { processos internos de prestação de } \\
\text { serviço da organização. }\end{array}$ & $\begin{array}{l}\text { Evidenciado que todas as propostas de soluções } \\
\text { tiveram o foco na aproximação cidadã, } \\
\text { trabalhando os aspectos ou dimensões de } \\
\text { colaboração, transparência e memória. }\end{array}$ \\
\hline
\end{tabular}

A Tabela 6 apresenta algumas das propostas de soluções apontadas pelos participantes como resultados da execução do MAPAC para este estudo de caso, organizadas segundo os habilitadores de colaboração, transparência e memória.

Tabela 6. Exemplos de soluções para aproximação cidadã dos processos organizacionais apresentadas como resultado da execução do MAPAC

\begin{tabular}{|c|c|}
\hline Colaboração & 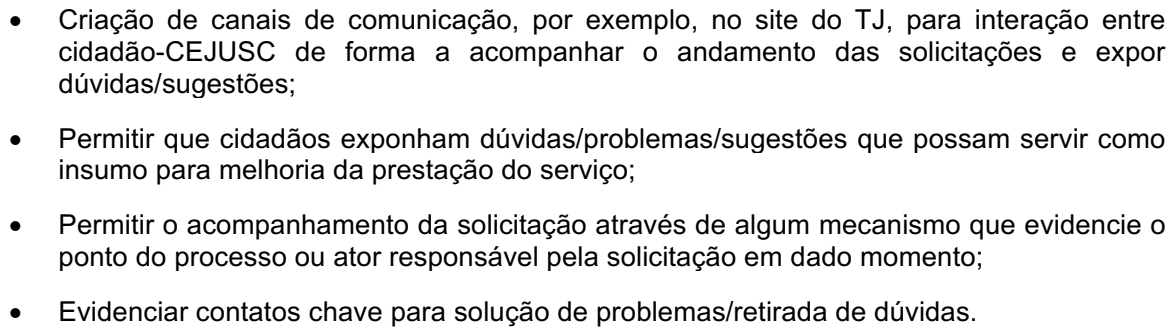 \\
\hline Transparência & $\begin{array}{l}\text { - Disponibilizar o status da solicitação e, após finalização da mediação, o resultado da } \\
\text { mesma às partes envolvidas no site do TJ ou em um portal de mediação (a ser criado); } \\
\text { - Disponibilizar uma versão de fácil entendimento (i.e., em termos que leigos consigam } \\
\text { entender) sobre o resultado da mediação aos cidadãos; } \\
\text { - Permitir o acompanhamento da solicitação através de algum mecanismo que evidencie o } \\
\text { ponto do processo ou ator responsável pela solicitação em dado momento; } \\
\text { - Criação de glossário com termos comuns do domínio para facilitar o entendimento das } \\
\text { partes envolvidas; }\end{array}$ \\
\hline Memória & $\begin{array}{l}\text { - Permitir o registro do ator que realizou qualquer modificação/interação com a solicitação } \\
\text { de melhoria do processo; } \\
\text { - Permitir que cidadãos exponham dúvidas/problemas/sugestões, por exemplo, no site do } \\
\text { TJ ou no portal de mediações (caso seja criado) que possam servir como insumo para } \\
\text { melhoria da prestação do serviço. }\end{array}$ \\
\hline
\end{tabular}




\subsection{Análise dos Resultados}

Os resultados apresentados no estudo indicaram que o MAPAC é viável para ser utilizado na análise dos processos de prestação de serviços públicos. A qualidade dos produtos gerados foi considerada como satisfatória e se encontra dentro do esperado para o estudo realizado. Foi evidenciada no estudo a satisfação dos participantes, pois o método ajuda a identificar os problemas e pensar nas possíveis soluções. Além disso, foi evidenciado que as informações passaram a dar visibilidade dos problemas enfrentados no processo, sendo possível elencar as causas e as respectivas soluções de melhorias.

Os participantes conseguiram executar todas as etapas propostas durante $\mathrm{o}$ estudo realizado para a avaliação do MAPAC. Entretanto, ainda não se pode afirmar que o método é eficaz ou eficiente, tendo em vista as limitações observadas no estudo de caso pelos participantes.

Em termos das dificuldades e/ou facilidades apresentadas, é aconselhável que o MAPAC seja executado por um especialista em processos de negócio, porém com restrições. Há necessidade de que o especialista tenha noção dos conceitos que compõem a disciplina de Democracia Eletrônica, tais como: os aspectos de colaboração, os aspectos de transparência e os aspectos de memória, identificação dos níveis de participação e interação cidadã desejados nos processos da organização, além dos habilitadores de aproximação cidadã. Há espaço para melhorias na forma de apresentação destes conceitos para que um profissional, que entenda apenas de BPM, possa executar o MAPAC sem maiores dificuldades.

O método foi capaz de produzir informações relevantes e úteis na percepção dos executores, por estarem alinhadas com os objetivos do CEJUSC-Capital e do NUPEMEC. Faz-se necessário observar que estas características que expressam a relevância e a utilidade das informações, não puderam ser evidenciadas sob a ótica dos stakeholders. As evidências demonstraram que nem todas as informações destacadas pelos participantes se mostraram completas para uma possível tomada de decisão por parte dos stakeholders. Por fim, foi evidenciado que nem todas as informações geradas pelos participantes se mostraram objetivas para o processo analisado.

É importante salientar que o estudo de caso exploratório apresentado neste trabalho de pesquisa produziu informações relevantes para os cenários do estudo. Entretanto, outros estudos e avanços na melhoria do MAPAC serão necessários para generalizar o método para outros contextos de aplicações.

\subsection{Validade e Limitações}

Segundo Yin (2015) e Antonio, Fornazin e Araujo (2018), a validade de um estudo de caso pode ser verificada em quatro dimensões: validade do constructo, validade interna, validade externa e confiabilidade. Nesta pesquisa, a validade do constructo foi garantida pelo uso de múltiplas fontes de evidência (pessoas, artefatos e observação), seu encadeamento em questões e variáveis a serem observadas durante a execução, e sua validação em um pré-teste realizado no INCA. Quanto à validade interna, os dados foram analisados com base nas variáveis observadas e explicações para as observações foram realizadas. Quanto à validação externa, ela pretenderá ser alcançada mediante a realização de novos estudos de caso, sendo os resultados deste estudo ainda limitados ao contexto de sua aplicação. Quanto à confiabilidade, o protocolo de estudo de caso foi 
empregado, bem como os resultados obtidos registrados e analisados, sendo esta publicação uma das possibilidades de seus resultados serem utilizados para novos estudos de caso em contextos similares.

Destacam-se ainda como limitações do estudo de caso realizado a falta de tempo do $1^{\circ}$ participante para executar o MAPAC em uma única sessão, o que consumiu 14 horas, aproximadamente. Outra limitação foi o fato dos participantes do estudo de caso não possuírem todos os conhecimentos necessários para execução do método, tais como: domínio da organização (unidade-caso) e conhecimento de Democracia Eletrônica e BPM. As variáveis relevância e utilidade foram avaliadas apenas pela ótica do pesquisador as quais haveria a necessidade de submetê-las aos stakeholders do NUPEMEC.

\section{Conclusões}

As organizações públicas buscam inovações e melhorias de seus processos para prestarem um serviço de qualidade ao cidadão. No entanto, ainda são incipientes os meios, as maneiras e as técnicas que são utilizadas para aproximar o cidadão de seus processos.

Este trabalho objetivou responder à questão inicial de como prover um método para análise de processos visando identificar propostas de soluções para aproximar o cidadão das organizações públicas prestadoras de serviços. Assim, a proposta deste trabalho de pesquisa foi conceber um método que utilizasse os conceitos das disciplinas de BPM e de Democracia Eletrônica as quais organizam um conjunto de habilitadores de aproximação cidadã para análise de um processo de prestação de serviço. O MAPAC foi dividido em 3 (três) etapas cujo objetivo é auxiliar um analista de processos a pensar em soluções, tecnológicas ou não, para aproximar o cidadão da organização pública a partir de seus processos.

Inicialmente foi realizado um pré-teste que serviu para ajustar o MAPAC, utilizando um dos processos de negócio de um hospital oncológico, o INCA. Com apoio de um dos stakeholders deste hospital foi possível analisar os produtos gerados (informações e as propostas de soluções) pelo próprio analista pesquisador que executou o método. Posteriormente, foi realizado um estudo de caso exploratório para avaliar o MAPAC, utilizando a modelagem de processo de prestação de serviço, fase préprocessual, do CEJUSC-Capital.

Os resultados do estudo de caso evidenciaram que o MAPAC se apresentou viável para análise de um processo público, com a qualidade satisfatória nos produtos gerados, além da satisfação dos participantes, no contexto do CEJUSC-Capital, além dos aspectos positivos e negativos apontados pelos participantes para futuras melhorias do método. $\mathrm{O}$ estudo evidenciou que as informações produzidas foram relevantes, úteis e completas, porém nem todas objetivas.

As observações realizadas pelos participantes permitiram dizer que a execução do MAPAC auxilia o especialista em processos e os stakeholders a pensarem em possíveis melhorias a serem implementadas nos processos da organização pública para aproximar o cidadão, como nos estudos realizados no INCA inicialmente e posteriormente, no CEJUSC-Capital. Há espaço para melhorias do MAPAC, apresentado como proposta de solução para aproximar o cidadão dos processos de 
prestação de serviço público, o que torna necessário ampliar os estudos por meio de outras aplicações.

Como trabalho futuro é sugerido que o MAPAC possa ser executado em contextos diferentes dos realizados neste trabalho, por exemplo, em outros CEJUSC da cidade do Rio de Janeiro ou em outras organizações públicas prestadoras de serviços ao cidadão. $\mathrm{O}$ objetivo é avaliar a viabilidade de execução do método e promover novos ajustes que se fizerem necessários, tornando o método o mais abrangente possível para ser executado em qualquer organização pública.

Outra proposta é a criação de um instrumento automatizado (artefato) em uma plataforma Web. Haveria necessidade de realizar um estudo com gestores para definir, além das funcionalidades e conceitos já apresentados no MAPAC, outras funcionalidades que o torne mais eficiente e aderente a outras organizações públicas. Também, para trabalhos futuros pode-se pensar em ampliar este estudo investigando outros habilitadores de aproximação cidadã que atuam nas melhorias de processos de prestação de serviços de uma organização pública. Considera-se para trabalhos futuros verificar outras possibilidades de dimensões ou aspectos de Democracia Eletrônica, além dos de colaboração, transparência e memória para que um analista de processos possa pensar e criar design de soluções para aproximação cidadã dos processos/serviços públicos. Além das propostas mencionadas, poderia ser pensada para trabalhos futuros, a criação de uma ou mais etapas, envolvendo o ciclo de vida de BPM, por exemplo, a fase de redesenho de um processo.

\section{Agradecimentos}

Renata Araujo é apoiada pelo CNPq por meio de Bolsa de Produtividade em Desenvolvimento Tecnológico e Extensão Inovadora, processo no 305060/2016-3.

\section{Referências}

ABPMP. Guia para o Gerenciamento de Processos de Negócio - Corpo Comum de Conhecimento (BPM CBOK V3.0). 1st ed. Cambridge, 2013.

ANTONIO, N.; FORNAZIN, M.; ARAUJO, R. Metodologia de Pesquisa de Estudo de Caso em Sistemas de Informação. Disponível em: $<$ http://portaldeconteudo.sbc.org.br/livros/index.php/sbc/catalog/view/7/10/35-1>. Acesso em: 20/6/2019.

ARAUJO, R.; CAPELLI, C.; DIIRR, B.; ENGIEL, P.; TAVARES, R. L. Democracia Eletrônica. In: M. Pimentel; H. Fuls (Eds.); Sistemas Colaborativos. 1st ed., p.110$121,2011$.

ARAUJO, R.; MAGDALENO, A. Social BPM: Processos de Negócio, Colaboração e Tecnologia Social. Simpósio Brasileiro de Sistemas de Informação (SBSI).4, p. 1-5, 2015.

ARAUJO, R.; TAHER, Y. Refining IT Requirements for Government-Citizen Coparticipation Support in Public Service Design and Delivery. In: P. Parycek; N. Edelmann (Eds.); Conference for E-Democracy and Open Governement. Anais... . 
p.61-72, 2014.

BASILI, R. V.; CALDIERA, G.; ROMBACH, H. D. Goal Question Metric (GQM) Approach. Encyclopedia of Software Engineering. v. 2, p.1-10, 2002.

BRASIL. Brasil. Lei $\quad \mathrm{N}^{\circ} 12.965 . \quad$ Disponível em: <http://www.planalto.gov.br/ccivil_03/_ato2011-2014/2014/lei/112965.htm>. Acesso em: 11/3/2018a.

BRASIL. Brasil. Decreto $\mathrm{N}^{\circ}$ 8.243. Disponível em: <http://www.planalto.gov.br/ccivil_03/_ato2011-2014/2014/decreto/d8243.htm>. Acesso em: 14/7/2018b.

BRASIL. Brasil. Lei $\quad \mathrm{N}^{\circ}$ 13.105. Disponível em: $<$ https://www.planalto.gov.br/ccivil_03/_ato2015-2018/2015/lei/113105.htm>. Acesso em: 3/10/2016.

BRASIL. Brasil. Decreto $\mathrm{n}^{\mathrm{o}}$ 8.638. Disponível em: <http://www.planalto.gov.br/ccivil_03/_ato2015-2018/2016/decreto/d8638.htm>. Acesso em: 14/7/2018.

BRASIL. Brasil. Lei $\quad N^{0}$ 13.460. Disponível em: <http://www.planalto.gov.br/ccivil_03/_ato2015-2018/2017/lei/L13460.htm>. Acesso em: $3 / 1 / 2018$.

CAPPELLI, C. Uma abordagem para transparência em processos organizacionais utilizando aspectos. 2009. 328 f. Tese (Doutorado em Informática). Pontifícia Universidade Católica do Rio de Janeiro-PUC. 2009.

CLASSE, T. DE M. DE. Um método para o design de jogos digitais baseados em processo para a prestação de serviços públicos. 2017. $154 \mathrm{f}$. Universidade Federal do Estado do Rio de Janeiro - UNIRIO. 2017.

DIIRR, B. Conversas sobre processos de prestação de serviços públicos. 2011.145 f. Dissertação (Mestrado em Informática). Universidade do Estado do Rio de JaneiroUNIRIO. 2011.

DIIRR, B.; ARAUJO, R.; CAPPELLI, C. Talking about Public Service Processes. (E. Tambouris, A. Macintosh, \& H. Bruijn, Eds.)Electronic Participation: Proceedings of the 3rd IFIP WG 8.5 International Conference, ePart 2011, Lecture Notes in Computer Science., 2011.

DIIRR, B.; ARAUJO, R.; CAPPELLI, C. Encouraging Society Participation Through Conversations About Public Service Processes. International Journal of Electronic Government Research, v. 10, n. 2, p. 22-42, 2014.

DIIRR, B.; ENGIEL, P.; TAVARES, R.; ARAUJO, R. Soluções para ampliação da Democracia Eletrônica. Disponível em: <http://www.lbd.dcc.ufmg.br/colecoes/erirj/2010/03-63820_3.pdf>. Acesso em: 27/1/2017.

DUMAS, M.; ROSA, M. LA; MENDLING, J.; REIJERS, H. A. Fundamentals of Business Process Management. 2nd ed. Berlin, Heidelberg: Springer Berlin Heidelberg, 2018.

ENGIEL, P. Projetando o entendimento de modelos de processo de prestação de serviços públicos. 2012. Dissertação (Mestrado em Informática). Universidade Federal 
do Estado do Rio de Janeiro - UNIRIO. 2012.

GOMES, J. M. Promovendo a compreensão de regras em processos de prestação de serviços públicos utilizando a animação. 2011. 108 f. Dissertação (Mestrado em Informática). Universidade Federal do Estado do Rio de Janeiro - UNIRIO. 2011.

MACINTOSH, A.; WHYTE, A. Towards an evaluation framework for eParticipation. Transforming Government: People, Process and Policy, v. 2, n. 1, p. 16-30, 2008.

MAGDALENO, A.; ARAUJO, R.; BORGES, M. A maturity model to promote collaboration in business processes. International Journal of Business Process Integration and Management, v. 4, n. 2, p. 111, 2009.

NIEHAVES, B.; MALSCH, R. Democratizing Process Innovation? On Citizen Involvement in Public Sector BPM. (M. A. Wimmer, H. J. Scholl, M. Janssen, \& R. Traunmüller, Eds.)Electronic Government: Proceedings of the 8th IFIP WG 8.5 International Conference, EGOV 2009, Lecture Notes in Computer Science., 2009.

NOGRAŠEK, J.; VINTAR, M. Observing organisational transformation of the public sector in the e-government era. Transforming Government: People, Process and Policy, v. 9, n. 1, p. 52-84, 2015.

PIRES, E. Método de Análise de Processos para Aproximação Cidadã (MAPAC). Disponível em: <http://ciberdem.uniriotec.br/wpcontent/uploads/sites/20/2018/07/Book-MAPAC_V10.pdf>. Acesso em: 25/8/2018.

RACZYŃSKA, M. Process management in Public administration. Acta Universitatis Nicolai Copernici, v. 42, n. 4, p. 79-91, 2015.

SELL, M. M. Regra Clara: Uma proposta de design de artefato para compreensão de regras de negócio em processos de prestação de serviços públicos. $2016.97 \mathrm{f}$. Dissertação (Mestrado em Informática). Universidade Federal do Estado do Rio de Janeiro - UNIRIO. 2016.

SELL, M. M.; ARAUJO, R. Regras de Negócio para Cidadãos: Compreensão e Comunicação Business Rules for Citizens : Comprehension and Communication. , p. 3$5,2015$.

SERRANO, D. B. Identificação de requisitos de apoio à gestão de conhecimento: uma análise holística e intencional dos processo de negócio. 2010. 133 f. Dissertação (Mestrado em Informática). Universidade do Estado do Rio de Janeiro-UNIRIO. 2010.

SERRANO, D. B.; SANTOS, L. Roteiro para levantamento de requisitos para o apoio à gestão de conhecimento através de processos de negócios. $2007.71 \mathrm{f}$. UNIRIO-Universidade do Estado do Rio de Janeiro. 2007.

SHARP, A.; MCDERMOTT, P. Workflow Modeling: Tools for Process Improvement and Application Development, Second Edition. 2009.

SILVA, J.; PÓS-GRADUAÇÃO, P. DE; PPGI, I.; ARAUJO, R. Um Método de Elicitação de Requisitos para Ambientes Virtuais de Participação Social Alternative Title: A Elicitation Method Requirements for Virtual Environments Social Participation. , 2016.

SILVA, S. Graus de participação democrática no uso da Internet pelos governos das capitais brasileiras. Opinião Pública, v. 11, n. 2, p. 450-468, 18. Oct. 2005. 
TAVARES, R. L. Visualizações para apoiar a compreensão de discussões políticas. 2012. 108 f. Dissertação (Mestrado em Informática). Universidade Federal do Estado do Rio de Janeiro - UNIRIO. 2012.

TAVARES, R. L.; PIMENTEL, M.; MENDES DE ARAUJO, R. Visualizing Clashes and Alliances in Social Networks of Political Discussions. Social Networking, v. 3, p. 94-101, 2014.

YIN, R. K. Estudo de Caso: planejamento e métodos. 5th ed. Porto Alegre: Bookman, 2015. 


\section{Anexo:}

Tabela 7. Questões para reflexão sobre o Habilitador de Colaboração

\begin{tabular}{|c|c|c|c|c|c|c|}
\hline \multicolumn{2}{|c|}{ HABILITADOR - COLABORAÇÃO } & \multicolumn{5}{|c|}{$\begin{array}{c}\text { Níveis de participação } \\
\text { cidadã desejados }\end{array}$} \\
\hline $\begin{array}{l}\text { Aspectos de } \\
\text { Colaboração }\end{array}$ & Questões para Aproximação Cidadã & $1^{\circ}$ & $2^{\circ}$ & $3^{\circ}$ & $4^{0}$ & $5^{\circ}$ \\
\hline Comunicação & $\begin{array}{l}\text { 1. Considerando o nível de participação desejado, existe a } \\
\text { possibilidade de comunicação entre o cidadão e os demais } \\
\text { atores do processo? } \\
\text { 2.Para o nível de participação desejado, seria possível pensar em } \\
\text { canais de comunicação tecnológicos ou não, no processo atual, } \\
\text { para que o cidadão possa interagir com os demais atores do } \\
\text { processo? (nota: veja a questão anterior) } \\
\text { 3. Quais seriam estes canais de comunicação? (nota: veja a } \\
\text { questão anterior) } \\
\text { 4.Em algum ponto do processo seria possível estabelecer estes } \\
\text { canais de comunicação entre o cidadão e os demais atores do } \\
\text { processo? (nota: veja a questão anterior) } \\
\text { 5.De que forma seria o funcionamento destes canais de } \\
\text { comunicação? (nota: veja a questão anterior) } \\
\text { 6. Tendo em vista, ainda, o nível de participação desejado, haveria } \\
\text { como estabelecer um canal de comunicação para que o cidadão } \\
\text { e os demais atores do processo possam compartilhar } \\
\text { conhecimento informal como: ideias, opiniões, críticas e } \\
\text { discussões de questões relevantes para melhoria do processo? }\end{array}$ & \multirow{3}{*}{ 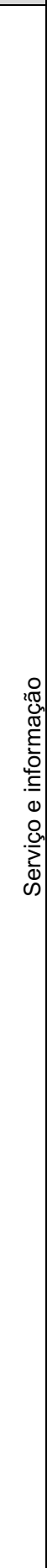 } & \multirow{3}{*}{ 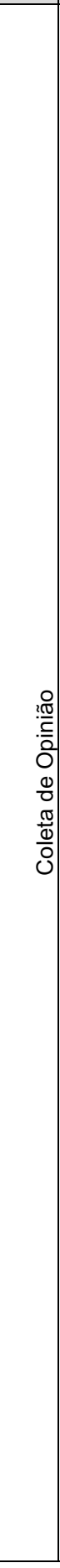 } & \multirow{3}{*}{ 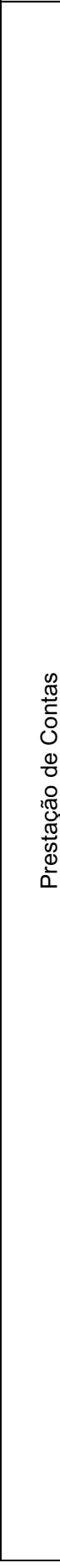 } & \multirow{3}{*}{ 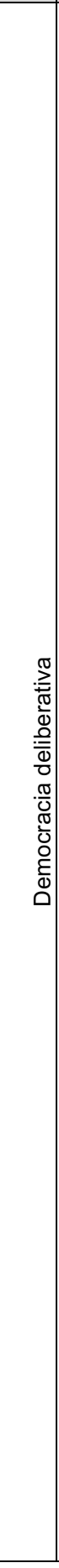 } & \multirow{3}{*}{ 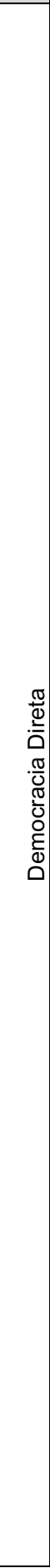 } \\
\hline Coordenação & $\begin{array}{l}\text { 7. Considerando o nível de participação desejado, haveria a } \\
\text { possibilidade de o cidadão, no processo atual, colaborar com } \\
\text { algum artefato (ex.: documentos) durante a sua execução? } \\
\text { 8. Se houvesse essa possibilidade, com quais artefatos o cidadão } \\
\text { poderia colaborar durante a execução do processo? (nota: veja a } \\
\text { questão anterior) } \\
\text { 9. Ainda, para o nível de participação desejado, haveria como o } \\
\text { cidadão colaborar com a evolução do item de trabalho (ex.: } \\
\text { protocolo aberto, processo aberto, chamado aberto, atendimento } \\
\text { aberto, prontuário aberto, etc.) do processo durante a sua } \\
\text { execução? (nota: veja a questão anterior) } \\
\text { 10.Em que pontos da execução do processo o cidadão poderia } \\
\text { colaborar com o item de trabalho? (nota: veja a questão anterior) } \\
\text { 11.De que forma o cidadão poderia incorporar (integrar) os seus } \\
\text { artefatos (ex.: documentos) ao item de trabalho do processo ora } \\
\text { em execução? (nota: veja a questão anterior) } \\
\text { 12.Levando em consideração o nível de participação almejado, } \\
\text { existiriam mecanismos ou formas possíveis de inserir o cidadão } \\
\text { nas discussões de melhoria do processo? }\end{array}$ & & & & & \\
\hline Percepção & $\begin{array}{l}\text { 13. Considerando o nível de participação desejado, no processo } \\
\text { atual, haveria como fazer o cidadão saber quem são os demais } \\
\text { atores do processo? } \\
\text { 14.Quais seriam estas formas de o cidadão saber quem são os } \\
\text { demais atores do processo? (nota: veja a questão anterior) } \\
\text { 15.Pensando no nível de participação desejado, o cidadão teria } \\
\text { como reconhecer quais são as atividades executados por cada } \\
\text { um dos demais atores do processo? (nota: veja a questão } \\
\text { anterior) } \\
\text { 16. Tendo em vista o nível de participação desejado, há no } \\
\text { processo atual uma pessoa para o qual o cidadão possa se } \\
\text { reportar durante a execução do processo? } \\
\text { 17. Haveria como pensar em mecanismos para que o cidadão } \\
\text { perceba que suas contribuições (sugestões) de melhorias do } \\
\text { processo estejam em funcionamento, considerando o nível de } \\
\text { participação desejado? } \\
\text { 18. Baseado no nível de participação desejado haveria formas de } \\
\text { divulgar para o cidadão que suas contribuições (sugestões) } \\
\text { representaram melhorias na execução do processo da } \\
\text { organização? (nota: veja a questão anterior) }\end{array}$ & & & & & \\
\hline
\end{tabular}


Tabela 8. Questões para reflexão sobre o Habilitador de Transparência

\begin{tabular}{|c|c|c|c|c|c|c|}
\hline \multicolumn{2}{|c|}{ HABILITADOR - TRANSPARÊNCIA } & \multicolumn{5}{|c|}{$\begin{array}{l}\text { Niveis de participação } \\
\text { cidadã desejados }\end{array}$} \\
\hline $\begin{array}{c}\text { Graus de } \\
\text { Transparência- } \\
\text { Características }\end{array}$ & Questões para Aproximação Cidadã & $1^{0}$ & $2^{\circ}$ & $3^{\circ}$ & $4^{\circ}$ & $5^{\circ}$ \\
\hline $1^{\circ}$ - Acessibilidade & $\begin{array}{l}\text { 1.Considerando o nível de participação desejado pela } \\
\text { organização, quais as informações que poderiam ser geradas } \\
\text { durante a execução da instância do processo para o cidadão? } \\
\text { 2.As informações geradas pela execução do processo atual } \\
\text { estão disponíveis para o cidadão? (nota: veja a questão } \\
\text { anterior) } \\
\text { 3.De que forma seria o acesso a essas informações pelo o } \\
\text { cidadão? (nota: veja a questão anterior) } \\
\text { 4.Como seria a visualização dessas informações pelo cidadão? } \\
\text { (nota: veja a questão anterior) } \\
\text { 5.Para o nível de participação desejado, como poderiam ser } \\
\text { exportadas as informações geradas pela execução do } \\
\text { processo em diversos formatos para o cidadão (Ex.: ".txt", } \\
\text { ".csv", ". pdf", ".doc")? }\end{array}$ & \multirow{5}{*}{ 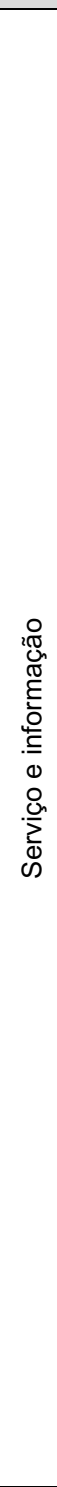 } & \multirow{5}{*}{$\begin{array}{l}\frac{2}{0} \\
: \frac{\pi}{0} \\
0 \\
0 \\
\frac{0}{0} \\
\frac{\pi}{0} \\
\frac{0}{0} \\
0\end{array}$} & \multirow{5}{*}{ 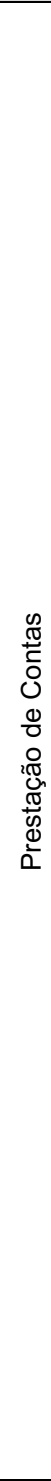 } & \multirow{5}{*}{ 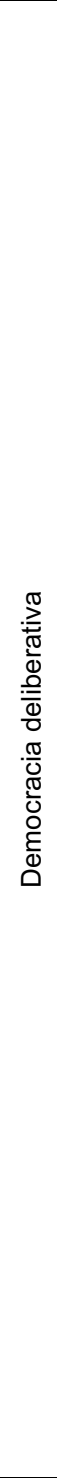 } & \multirow{5}{*}{$\begin{array}{l}\frac{\pi}{0} \\
\frac{0}{0} \\
\frac{\pi}{0} \\
\frac{\pi}{0} \\
\frac{\pi}{0} \\
\frac{0}{0} \\
0\end{array}$} \\
\hline $2^{\circ}$ - Usabilidade & $\begin{array}{l}\text { 6.As informações geradas pela execução do processo atual são } \\
\text { intuitivas para o cidadão? } \\
\text { 7.O cidadão compreende as informações que são geradas pela } \\
\text { execução do processo atual? } \\
\text { 8.De que forma as informações geradas pela execução do } \\
\text { processo atual poderiam ser intuitivas e de fácil compreensão } \\
\text { para o cidadão, levando em conta o nível de participação } \\
\text { desejado pela organização? (nota: veja as questões } \\
\text { anteriores) }\end{array}$ & & & & & \\
\hline $3^{\circ}$ - Informativo & $\begin{array}{l}\text { 9.O cidadão compreende claramente as informações sobre as } \\
\text { atividades que deve executar durante a sua interação com } \\
\text { processo atual? } \\
\text { 10.Levando em consideração o nível de participação desejado, } \\
\text { quais seriam então os meios ou as formas para que as } \\
\text { informações sobre as atividades a serem executadas se } \\
\text { tornem claras para o cidadão? (nota: veja a questão anterior) } \\
\text { 11.O cidadão poderia visualizar sugestões, recursos ou } \\
\text { informações para execução das atividades do processo, } \\
\text { considerando o nível de participação desejado? (nota: veja a } \\
\text { questão anterior) }\end{array}$ & & & & & \\
\hline $4^{\circ}$ - Entendimento & $\begin{array}{l}\text { 12.Poderia existir um glossário/dicionário/help sobre os termos } \\
\text { utilizados na execução do processo que auxiliasse o cidadão } \\
\text { no seu entendimento, tendo em vista o nível de participação } \\
\text { desejado? }\end{array}$ & & & & & \\
\hline $5^{\circ}$ - Auditabilidade & $\begin{array}{l}\text { 13.Considerando o nível de participação desejado, seria factível } \\
\text { o cidadão auditar as informações geradas pela execução do } \\
\text { processo? } \\
\text { 14.Considerando o nível de participação desejado pela } \\
\text { organização, seria possível o cidadão auditar a execução do } \\
\text { processo? } \\
\text { 15.De que forma o cidadão pode realizar ou participar dessas } \\
\text { auditorias? (nota: veja as questões anteriores) }\end{array}$ & & & & & \\
\hline
\end{tabular}

Tabela 9. Questões para reflexão sobre o Habilitador de Memória

\begin{tabular}{|c|c|c|c|c|c|c|}
\hline \multicolumn{2}{|c|}{ HABILITADOR - MEMÓRIA } & \multicolumn{5}{|c|}{$\begin{array}{l}\text { Niveis de participação } \\
\text { cidadã desejados }\end{array}$} \\
\hline Conhecimento & Questões para Aproximação Cidadã & $1^{\circ}$ & $2^{\circ}$ & $3^{\circ}$ & $4^{\circ}$ & $5^{\circ}$ \\
\hline $\begin{array}{l}\text { Formal ou } \\
\text { Explícito }\end{array}$ & $\begin{array}{l}\text { 1.Para o nível de participação almejado, haveria como se } \\
\text { registrar os históricos das melhorias realizadas no processo? } \\
\text { 2.De que forma o registro dos históricos (ex.: datas, } \\
\text { responsáveis, observações, etc.) de melhorias realizadas no } \\
\text { processo poderia ser feito para que qualquer ator do processo } \\
\text { possa consultar (ex.: documentos, processos mapeados, } \\
\text { etc.)? (nota: veja a questão anterior) }\end{array}$ & \multirow{2}{*}{ 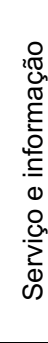 } & \multirow{2}{*}{ 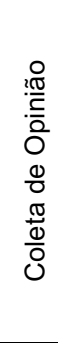 } & \multirow{2}{*}{ 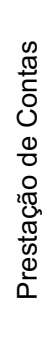 } & \multirow{2}{*}{ 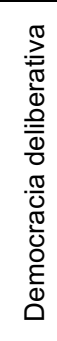 } & \multirow{2}{*}{ 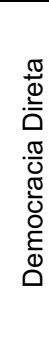 } \\
\hline Informal ou Tácito & $\begin{array}{l}\text { 3. Há meios para se registrar os históricos das ideias, opiniões, } \\
\text { críticas e discussões de questões relevantes para o processo } \\
\text { fornecidos pelo cidadão? }\end{array}$ & & & & & \\
\hline
\end{tabular}


Tabela 10. Questões para reflexão sobre o habilitador de Workflow

\begin{tabular}{|c|c|c|c|c|c|}
\hline HABILITADOR - WORKFLOW & \multicolumn{5}{|c|}{$\begin{array}{l}\text { Níveis de participação } \\
\text { cidadã desejados }\end{array}$} \\
\hline Questões para Aproximação Cidadã & $1^{\circ}$ & $2^{\circ}$ & $3^{\circ}$ & $4^{\circ}$ & $5^{\circ}$ \\
\hline $\begin{array}{l}\text { 1. Tendo em vista o nível de participação desejado, existiriam atividades as quais o } \\
\text { cidadão deveria estar representado (inserido) no modelo de processo atual da } \\
\text { organização? } \\
\text { 2. Baseando-se no nível de participação desejado, há no processo atual algum gargalo } \\
\text { de informação ou de serviço que levaria o cidadão a se deslocar para diversos } \\
\text { pontos (locais) da organização? } \\
\text { 3. Quais atividades ou informações poderiam ser simplificadas de tal forma a reduzir ou } \\
\text { eliminar os pontos de deslocamentos do cidadão, considerando o nível de } \\
\text { participação desejado? (nota: veja a questão anterior) }\end{array}$ & 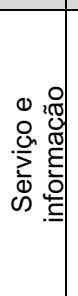 & 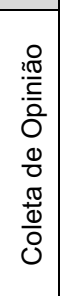 & 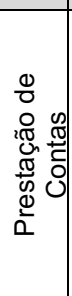 & $\begin{array}{l}\frac{\pi}{U} \\
\frac{\pi}{\pi} \\
\frac{\pi}{d}\end{array}$ & 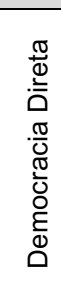 \\
\hline
\end{tabular}

Tabela 11. Questões para reflexão sobre o habilitador de TI

\begin{tabular}{|c|c|c|c|c|c|}
\hline HABILITADOR - TI & \multicolumn{5}{|c|}{$\begin{array}{l}\text { Níveis de participação } \\
\text { cidadã desejados }\end{array}$} \\
\hline Questões para Aproximação Cidadã & $1^{\circ}$ & $2^{\circ}$ & $3^{\circ}$ & $4^{\circ}$ & $5^{\circ}$ \\
\hline $\begin{array}{l}\text { 1.Considerando o nível de participação desejado, os sistemas atuais, que apoiam o } \\
\text { processo da organização, atenderiam as soluções propostas de aproximação cidadã } \\
\text { elencadas? } \\
\text { 2.Supondo que os sistemas atuais não apoiem ou apoiem parcialmente as soluções } \\
\text { propostas de aproximação cidadã, então, quais seriam as possíveis melhorias a } \\
\text { serem propostas? (nota: veja a questão anterior) } \\
\text { 3.Tendo em vista o nível de participação desejado, os sistemas atuais, que apoiam o } \\
\text { processo da organização, são de fácil utilização por parte do cidadão? } \\
\text { 4. Que melhorias poderiam ser pensadas para que os tornem mais fáceis de serem } \\
\text { utilizados por parte do cidadão? (nota: veja questão anterior) } \\
\text { 5.Para o nível de participação desejado, e possível pensar em aplicações para web } \\
\text { responsivas? (nota: veja a questão anterior) } \\
\text { 6.Levando em consideração o nível de participação desejado, quais seriam as } \\
\text { tecnologias inovadoras em aplicações mobile que poderiam auxiliar o cidadão a } \\
\text { interagir com os processos da organização? (nota: veja questão anterior) }\end{array}$ & 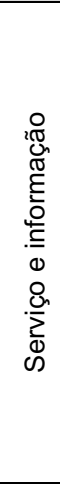 & 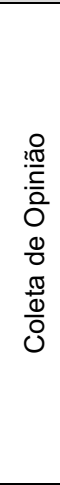 & 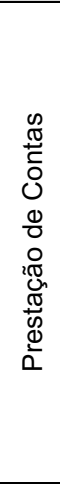 & 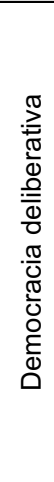 & 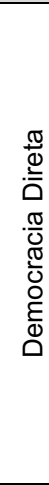 \\
\hline
\end{tabular}

Tabela 12. Questões para reflexão sobre o habilitador de Motivação e Métrica

\begin{tabular}{|c|c|c|c|c|c|}
\hline HABILITADOR - MOTIVAÇÃO E MÉTRICA & \multicolumn{5}{|c|}{$\begin{array}{l}\text { Níveis de participação } \\
\text { cidadã desejados }\end{array}$} \\
\hline Questões para Aproximação Cidadã & $1^{\circ}$ & $2^{\circ}$ & $3^{\circ}$ & $4^{\circ}$ & $5^{\circ}$ \\
\hline $\begin{array}{l}\text { 1.Para o nível de participação desejado pela organização é possível incentivar os } \\
\text { demais atores do processo a melhorar o atendimento ao cidadão? } \\
\text { 2. De que forma os demais atores do processo poderiam ser incentivados na melhoraria } \\
\text { do atendimento ao cidadão? (nota: veja a questão anterior) } \\
\text { 3. Considerando o nível de participação desejado, as métricas atuais do processo } \\
\text { atenderiam as propostas de soluções para aproximação cidadã? } \\
\text { 4. Há formas para se medir as propostas de soluções para aproximação cidadã, } \\
\text { considerando o nível de participação desejado pela organização? (nota: veja a } \\
\text { questão anterior) } \\
\text { 5.Como esses indicadores poderiam ser coletados? (nota: veja a questão anterior) }\end{array}$ & 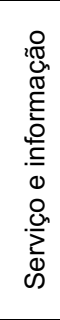 & $\begin{array}{l}\frac{0}{?} \\
\frac{\pi}{0} \\
\frac{\pi}{0} \\
0 \\
\frac{0}{0} \\
\frac{\pi}{0} \\
\frac{\pi}{0} \\
\frac{0}{0}\end{array}$ & 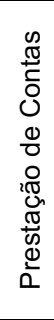 & 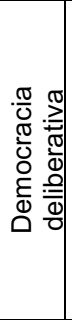 & 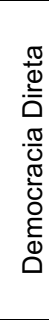 \\
\hline
\end{tabular}


Tabela 13. Questões para reflexão sobre o habilitador de RH

\begin{tabular}{|c|c|c|c|c|c|}
\hline HABILITADOR - RH & \multicolumn{5}{|c|}{$\begin{array}{l}\text { Níveis de participação } \\
\text { cidadã desejados }\end{array}$} \\
\hline Questões para Aproximação Cidadã & $1^{\circ}$ & $2^{\circ}$ & $3^{\circ}$ & $4^{\circ}$ & $5^{\circ}$ \\
\hline $\begin{array}{l}\text { 1.Para o nível de participação cidadã desejado, os demais atores do processo atual, } \\
\text { estariam conscientizados sobre a importância de um bom atendimento ao cidadão? } \\
\text { 2. Como conscientizar os demais atores do processo sobre a importância do } \\
\text { atendimento ao cidadão, considerando o nível de participação desejado? (nota: veja } \\
\text { a questão anterior) } \\
\text { 3. Tendo em vista o nível de participação desejado, os demais atores do processo } \\
\text { estariam capacitados para interagir com o cidadão? } \\
\text { 4.De que forma a organização poderia promover a capacitação dos demais atores do } \\
\text { processo para interagir melhor com o cidadão, considerando o nível de participação } \\
\text { desejado? (nota: veja a questão anterior) }\end{array}$ & 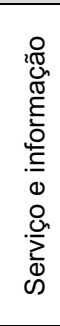 & $\begin{array}{l}\frac{0}{0} \\
\frac{1}{\circ} \\
0 \\
0 \\
\frac{0}{0} \\
\frac{\pi}{0} \\
\frac{\pi}{0} \\
0\end{array}$ & 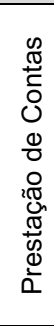 & 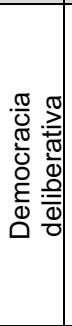 & 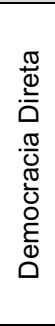 \\
\hline
\end{tabular}

\section{Tabela 14. Questões para reflexão sobre o habilitador de Políticas e Regras}

\begin{tabular}{|c|c|c|c|c|c|}
\hline HABILITADOR - POLÍTICAS E REGRAS & \multicolumn{5}{|c|}{$\begin{array}{l}\text { Niveis de participação } \\
\text { cidadã desejados }\end{array}$} \\
\hline Questões para Aproximação Cidadã & $1^{\circ}$ & $2^{\circ}$ & $3^{\circ}$ & $4^{\circ}$ & $5^{\circ}$ \\
\hline $\begin{array}{l}\text { 1.Para o nível de participação desejado, as propostas de soluções para aproximação } \\
\text { cidadã infringiriam de alguma forma as normas, as leis ou os regulamentos que se } \\
\text { impõem ao processo atual? } \\
\text { 2. Como as soluções propostas de aproximação cidadã poderiam ser alteradas de tal } \\
\text { forma que não comprometesse o nível de participação cidadã desejado pela } \\
\text { organização? (nota: veja a questão anterior) } \\
\text { 3.As propostas de soluções para aproximação cidadã impactariam de alguma forma as } \\
\text { políticas de governança da organização que se impõem ao processo atual? (nota: } \\
\text { verificar se a organização dispõe de uma política de governança para o processo em } \\
\text { análise) } \\
\text { 4. Há como pensar em outras alternativas de soluções de aproximação cidadão para } \\
\text { que não afete a política de governança da organização, tendo em vista o nível de } \\
\text { participação desejado? (nota: veja a questão anterior) }\end{array}$ & 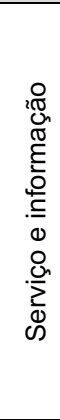 & $\begin{array}{l}\frac{0}{0} \\
\frac{\pi}{\overline{0}} \\
0 \\
0 \\
\frac{0}{0} \\
\frac{\pi}{0} \\
0\end{array}$ & 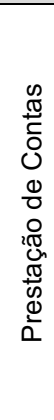 & 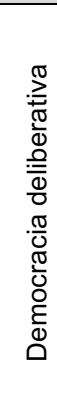 & $\begin{array}{l}\frac{\pi}{0} \\
\stackrel{0}{0} \\
\frac{\pi}{0} \\
\frac{\pi}{0} \\
\stackrel{0}{0} \\
\stackrel{0}{0} \\
0\end{array}$ \\
\hline
\end{tabular}

\section{Tabela 15. Questões para reflexão sobre o habilitador de infraestrutura}

\begin{tabular}{|c|c|c|c|c|c|}
\hline HABILITADOR - INFRAESTRUTURA & \multicolumn{5}{|c|}{$\begin{array}{l}\text { Níveis de participação } \\
\text { cidadã desejados }\end{array}$} \\
\hline Questões para Aproximação Cidadã & $1^{\circ}$ & $2^{\circ}$ & $3^{\circ}$ & $4^{\circ}$ & $5^{\circ}$ \\
\hline $\begin{array}{l}\text { 1. Considerando o nível de participação desejado, a infraestrutura atual atenderia as } \\
\text { propostas de soluções para aproximação cidadã? } \\
\text { 2. Que alternativas de infraestrutura poderiam ser pensadas para atender as propostas } \\
\text { de soluções para aproximação cidadã? (nota: veja a questão anterior) } \\
\text { 3.Em quais pontos do processo haveria a necessidade de criar, alterar ou incrementar } \\
\text { a infraestrutura da organização para atender as soluções propostas, considerando o } \\
\text { nível de participação desejado? } \\
\text { 4.De que forma seria essa infraestrutura? (nota: veja a questão anterior) }\end{array}$ & 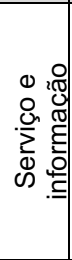 & $\begin{array}{l}\frac{0}{0} \\
\frac{\pi}{\mathbb{2}} \\
\frac{\pi}{0} \\
\end{array}$ & 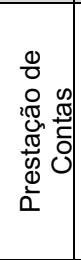 & 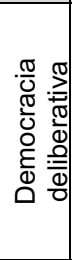 & 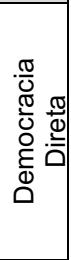 \\
\hline
\end{tabular}

